\title{
Increased Urban Resilience to Climate Change-Key Outputs from the RESCCUE Project
}

\author{
Marc Velasco 1,*(D), Beniamino Russo ${ }^{1,2}$, Robert Monjo ${ }^{3} \mathbb{D}$, César Paradinas $^{3}$, \\ Slobodan Djordjević ${ }^{4}\left(\mathbb{D}\right.$, Barry Evans ${ }^{4}$, Eduardo Martínez-Gomariz ${ }^{5}{ }^{\circledR}$, \\ Maria Guerrero-Hidalga ${ }^{5}{ }^{\circledR}$, Maria Adriana Cardoso ${ }^{6}$, Rita Salgado Brito ${ }^{6}$ and David Pacheco ${ }^{5}$ \\ 1 Aquatec, SUEZ Advanced Solutions, Urban Drainage and Resilience Direction, 08038 Barcelona, Spain; \\ brusso@aquatec.es \\ 2 Group de Ingeniería Hidráulica y Ambiental (GIHA) (Group of Hydraulic and Environmental Engineering), \\ Escuela Universitaria Politécnica de La Almunia, Universidad de Zaragoza, \\ 50100 La Almunia de Doña Godina, Spain \\ 3 FIC-Climate Research Foundation, 28013 Madrid, Spain; rma@ficlima.org (R.M.); cesar@ficlima.org (C.P.) \\ 4 Centre for Water Systems, University of Exeter, Exeter EX4 4QF, UK; S.Djordjevic@exeter.ac.uk (S.D.); \\ B.Evans@exeter.ac.uk (B.E.) \\ 5 Cetaqua-Water Technology Centre, Cornellà de Llobregat, 08940 Barcelona, Spain; \\ eduardo.martinez@cetaqua.com (E.M.-G.); maria.guerrero@cetaqua.com (M.G.-H.); \\ david.pacheco.ext@externalpartner.com (D.P.) \\ 6 LNEC-National Laboratory of Civil Engineering, 1700-066 Lisbon, Portugal; macardoso@lnec.pt (M.A.C.); \\ rsbrito@lnec.pt (R.S.B.) \\ * Correspondence: marc.velasco@suez.com
}

Received: 10 November 2020; Accepted: 24 November 2020; Published: 26 November 2020

\begin{abstract}
RESCCUE is an H2020 research project that aims to help cities around the world to become more resilient to physical, social, and economic challenges, using the water sector as the central point of the approach. Since 2016, RESCCUE has been developing methodologies and tools to support cities increase their resilience. The three RESCCUE cities, Barcelona, Bristol, and Lisbon, have become a testing platform for the cutting-edge technologies developed in RESCCUE but these are also ready to be deployed to different types of cities, with different climate change pressures. This paper presents some of the main outputs generated by RESCCUE. From climate change scenarios to dissemination tools, and from sectorial models to Resilience Action Plans (RAPs), the outputs that have been produced are very diverse, but special focus is put on the urban water cycle and urban floods. All the project results have a common goal: to increase the resilience of cities from around the world, by offering the methodologies and tools so anyone can take advantage of using them and replicate the RESCCUE results.
\end{abstract}

Keywords: urban resilience; climate change; urban services; water cycle; adaptation; disaster risk management

\section{Introduction}

We live in a world of cities, and that trend will continue in the future. Today, $54 \%$ of the world's population live in urban areas, a proportion that is expected to increase to $66 \%$ by 2050 [1]. In addition, climate change is adding pressures and uncertainties that pose challenges to society, economy, and environment. This is especially critical in urban areas, where climate change can affect basic urban services, such as water or energy supply, affecting the capacity of cities of functioning in a normal way [2]. As the United Nations have stated, managing urban areas has become one of the most important development challenges of the 21st century [1]. 
Cities face a growing range of adversities and challenges in the 21st century, and increasing urban resilience is the only way to survive and adapt to the coming shocks and stresses that may occur [3]. In this context, the RESCCUE (RESilience to cope with Climate Change in Urban arEas-a multisectoral approach focusing on water) project aimed to assess current and future resilience (related to future climate change scenarios) through a multisectoral approach, taking water sector as the focus.

Since 2016, RESCCUE has been developing methodologies and tools to support cities increase their resilience. The three RESCCUE cities, Barcelona, Bristol, and Lisbon, have become a testing platform for the cutting-edge technologies developed in RESCCUE but these are also ready to be deployed to different types of cities, with different climate change pressures.

The three research sites represent different challenges in terms of urban resilience building. These research sites have been selected due to their strong involvement with urban resilience as demonstrated by their selection and participation in the 100 Resilient Cities program funded by the Rockefeller Foundation. In addition, the three cities identified water-related risks as crucial in their hazard analysis, which became a common feature that allowed the RESCCUE methodology to be built.

The RESCCUE project was implemented through a set of eight WPs (work packages) described below (WP1 to WP6 is where the technical work is focused, whereas WP7 deals with communication and exploitation and WP8 is related to project management). Figure 1 depicts the project structure adopted by RESCCUE, specifying the relations among WPs and the main outputs.

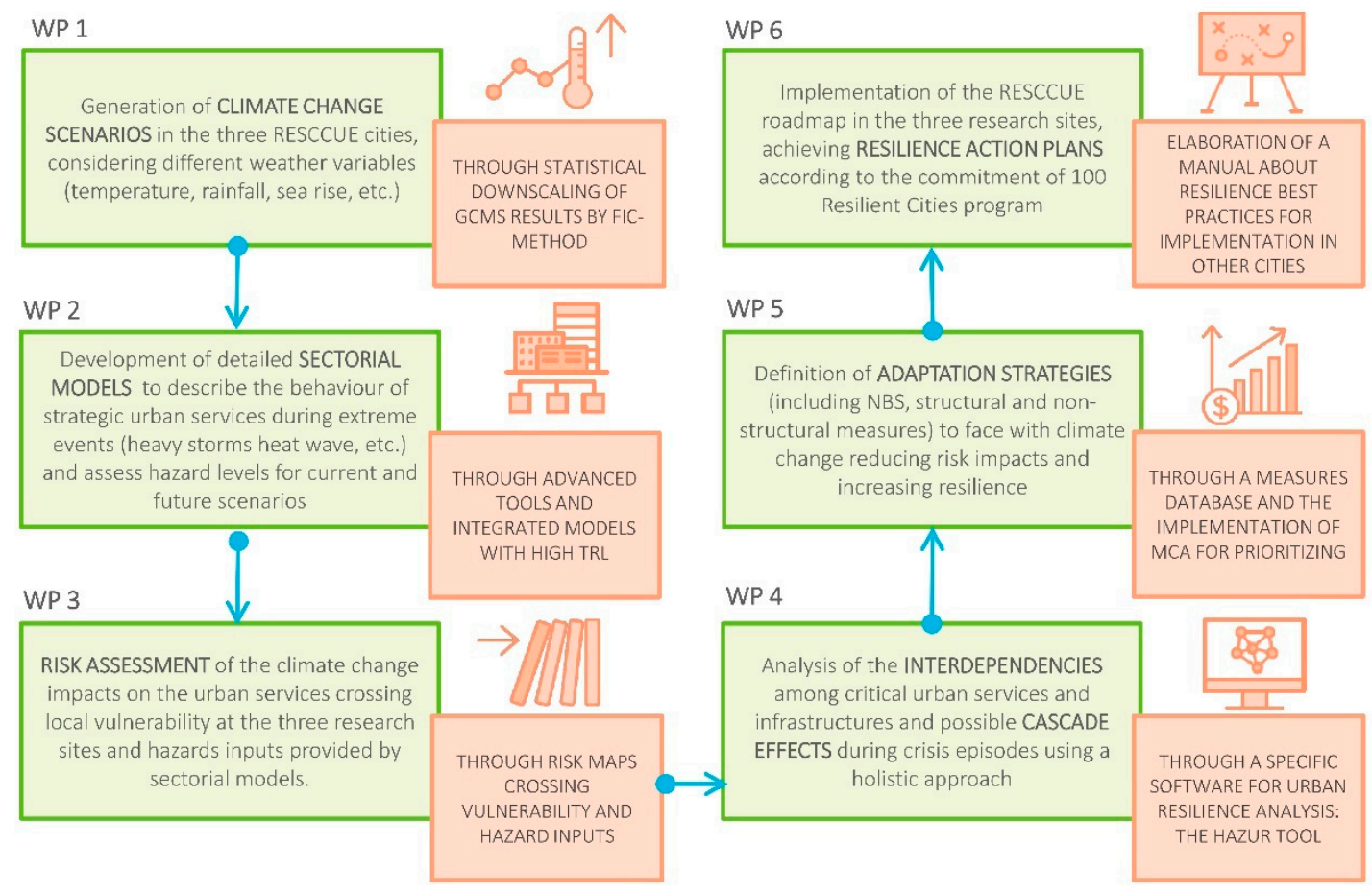

Figure 1. Resilience to Cope with Climate Change in Urban Areas (RESCCUE) Project structure and technical details. Source: [4].

This paper aims to present some of the variety of outputs generated by the RESCCUE project, such as climate change scenarios, dissemination tools, sectorial models, and Resilience Action Plans (RAPs). In the following sections the most relevant RESCCUE results can be seen, together with some of the technical details attached to them and their implementation on the three RESCCUE cities.

Nevertheless, as stated before, RESCCUE does not intend to be limited to Barcelona, Bristol and Lisbon. This is why all the RESCCUE results are showcased in the RESCCUE Toolkit (www.toolkit. resccue.eu), where any other city can take advantage of the work done in RESCCUE to replicate its results. 


\section{Climate Change Scenarios and Risk Assessment}

\subsection{Summary of Climate Change Results in RESCCUE Cities}

RESCCUE's basic input for the proper development of the project consists of abundant, long and reliable climate data, both observations and future climate projections. Aside from almost 300 analysed weather stations, RESCCUE has worked with downscaled Earth System Models (ESM) of the Coupled Model Intercomparison Project-Phase 5 (CMIP5, used in the 5th Intergovernmental Panel on Climate Change-IPCC-Assessment Report), under the two main Representative Concentration Pathway (RCP) scenarios: RCP4.5 and RCP8.5. A total of 10 ESMs (with daily timescale) were used to estimate the spread uncertainty of the climate variables through an ensemble strategy: ACCESS1-0, BCC-CSM1-1, CanESM2, CNRM-CM5, GFDL-ESM2M, HADGEM2-CC, MIROC-ESM-CHEM, MPI-ESM-MR, MRI-CGCM3, NorESM1-M. To obtain local time series of the past (simulations) and future climate (projections), the FICLIMA statistical downscaling method was applied to the large-scale model outputs [5]. The downscaled outputs were corrected afterwards with long quality observations and different transfer functions [6,7], obtaining therefore projections that represent better the local conditions of the climate. These future projections were also treated, together with observations, not only to obtain climatic values but also trends of different extreme weather events such as Heatwaves, Tropical nights, or Extreme rainfall in order to assess at both time scales and help cities grow more resilient towards these hazards.

\subsubsection{Changes in Mean Climate}

With a high statistical confidence ( $>95 \%)$, the climate projections obtained for all the three cities depict a future that points to a much warmer scenario, with an average increases about $+2{ }^{\circ} \mathrm{C}$ under RCP4.5, and up to $+4{ }^{\circ} \mathrm{C}$ under RCP8.5 by the end of the century (Table 1), and up to $+1{ }^{\circ} \mathrm{C}$ by 2030 [8]. However, this is not the case for rainfall or wind, where no significant changes on average regimes are expected in the future, with the exception of rainfall in Bristol, with moderate increases. Following these conclusions of warmer temperatures, snowfall is expected to suffer from a great decrease in its frequency in Barcelona and Bristol (Lisbon does not experience this phenomenon). Last but not least, mean sea level is also expected to experience a great increase in the three cities by the end of the century.

Table 1. Projected future climate for RESCCUE cities for the period 2071-2100. Annual values are shown following the structure "quantile10/median/quantile90" of the variable of interest. Changes are expressed, in the units specified, with respect to the historical value (1986-2015).

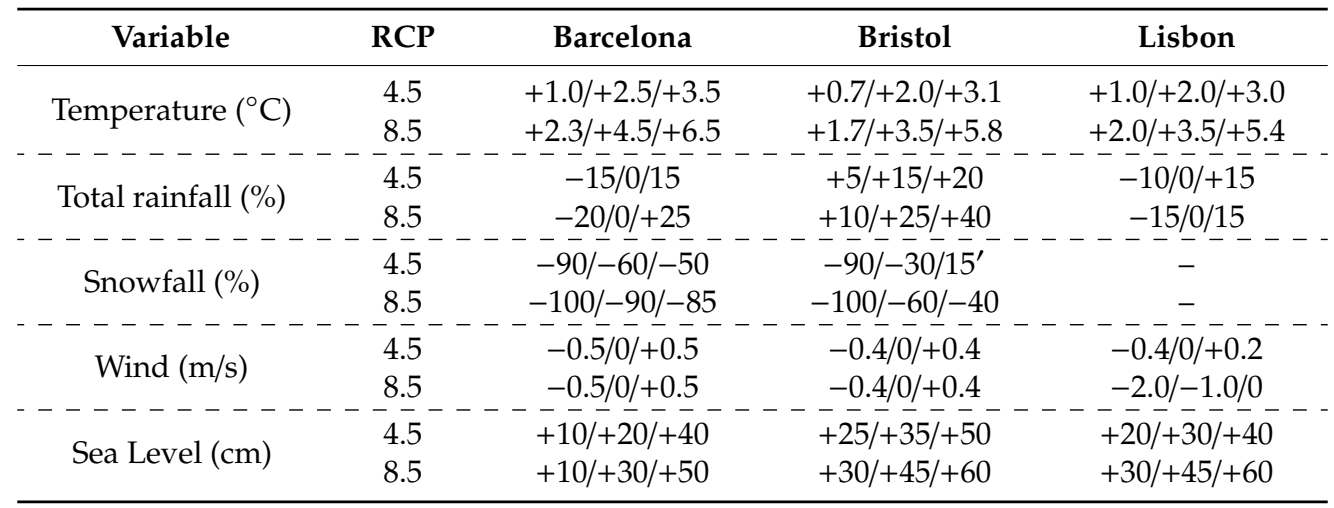

\subsubsection{Changes in Climate Extremes}

Regarding the extreme climate events, results are coherent with those obtained for the average climate: Temperature-related events will suffer a notable increase in the future for the three cities, with the Annual Maximum Temperature rising on average from $+3.0^{\circ} \mathrm{C}$ to $+5.0^{\circ} \mathrm{C}$ (e.g., Lisbon's $37-y e a r$ 
record maximum temperature was beaten on $04 / 08 / 18$, reaching $44^{\circ} \mathrm{C}$ ). Heatwave days and Tropical Nights will also see extraordinary increases (Table 2). Despite mean rainfall not being expected to suffer changes, extreme rainfall will do increase (hypothetically due to greater moist in the atmosphere); same for snowfall, that will be rarer but accumulations when happening could be thicker. On the other hand, Storm Surge is also expected to increase, mostly due to mean sea level rise. Finally, an acceleration of the hydrological cycle could increase water shortages due to a higher evapotranspiration, especially in Barcelona and Lisbon, where meteorological droughts are expected to be more frequent [9].

Table 2. Values of projected extreme events for RESCCUE cities for the years 2071-2100. Values with $\left(^{*}\right)$ correspond to a return period of 100 years. Values are shown following the structure "(historical)_quantile10/median/quantile90" of the variable of interest. Changes are expressed, in the units specified, with respect to the historical value (1986-2015).

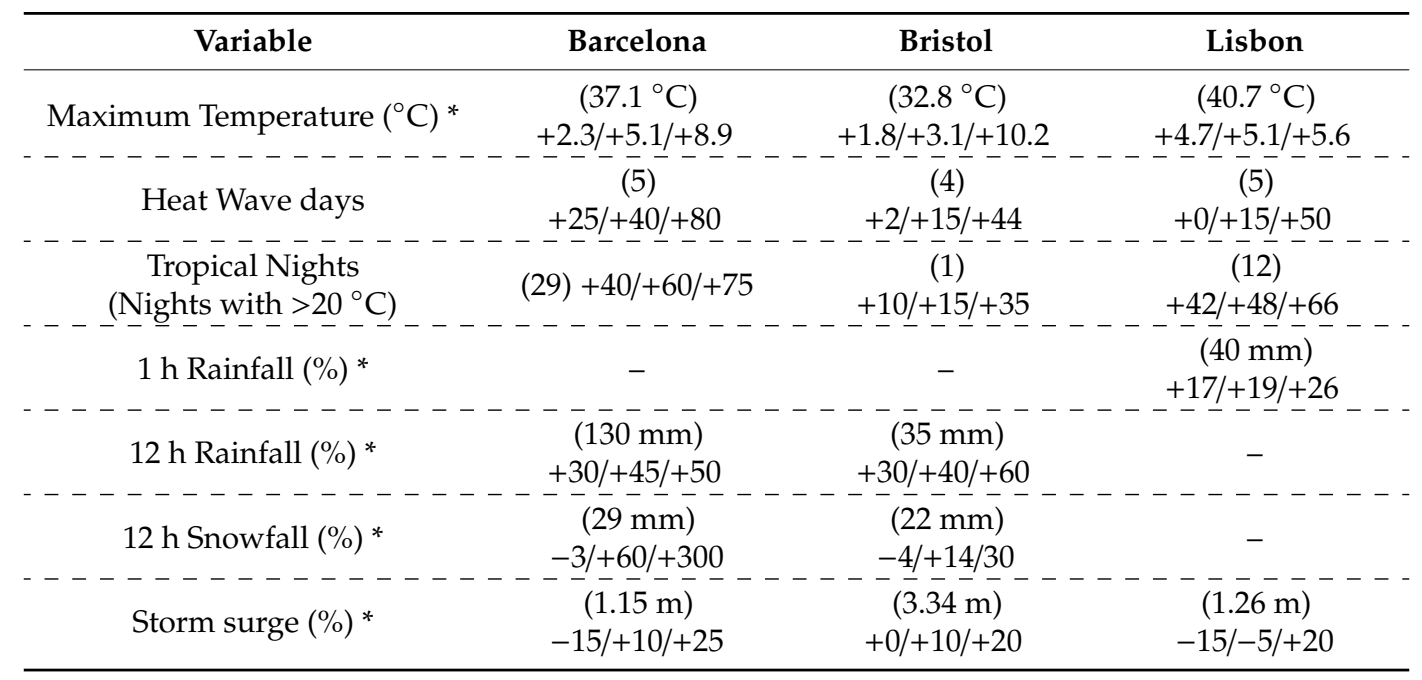

In general terms, climate change direction leads to a more extreme heat in the three RESCCUE cities, with a tendency towards more extreme rainfall events. On the one hand, extreme temperature could rise by up to $+5.0 \pm 2.5^{\circ} \mathrm{C}$ and heat wave days will experience an increase of about $+1000 \%$ (from 4-5 up to 40-50 days per year). On the other hand, daily and sub-daily extreme rainfall (with at least a 2-year return period) will increase in Barcelona and Bristol for about $+30 \%$. For Lisbon, this change is expected only for $1 \mathrm{~h}$ (or shorter) events. Moreover, extreme snowfall could also increase up to $40 \%$ for 100 years-return events in Barcelona during the next two decades. For the less extreme events (return periods from 2 to 10 years), snowfall would suffer a great decrease in Bristol and Barcelona due to the temperature rising.

Although significant changes in pluviometric drought are not expected (i.e., standardized precipitation index will not decrease), the water shortages (hydrological drought) will increment due to an increased evapotranspiration.

Regarding the windstorms, extreme gusts could increase in Barcelona up to $10 \pm 3 \%$ in the next two decades for all return periods, while storm surge is expected to rise in the three cities for 2 years-return events by 2100 . However, non-significant changes are projected for the extreme wave heights in the RESCCUE cities.

\subsection{Hazard Assessment Summary for the Three Cities}

Hazard assessment is the first step in the risk assessment process [10]. In this framework, some potential hazards for strategic urban services produced by a set of selected climate change pressures have been identified and selected depending on their significance and the interest in each research site (Table 3). The effects of these climate drivers on strategic urban services have been analyzed through detailed models and tools developed and calibrated within the project [11-15]. 
Moreover, the assessment of multiple hazards and risks was performed through the development of integrated or loosely coupled models and tools [16-19], where the outputs of certain models were used as inputs in others according to the scheme presented in Figure 2. The aim of the developed loosely coupled models was the multi-hazards and multi-risks assessment produced by urban fluvial, tidal and pluvial floods and the cascading effects on other urban services like the electrical, waste collection, and surface traffic system, as well as the effects on the receiving water bodies.

Table 3. Climate related hazards considered by sectorial and integrated (loosely coupled) models in the three RESCCUE sites.

\begin{tabular}{cccc}
\hline Impacted Service & Barcelona & Bristol & Lisbon \\
\hline Flooding & $\checkmark$ & $\checkmark$ & $\checkmark$ \\
Tidal and sea level rise & $\checkmark$ & $\checkmark$ & $\checkmark$ \\
Drought & $\checkmark$ & & \\
Water quality deterioration & $\checkmark$ & & \\
\hline
\end{tabular}

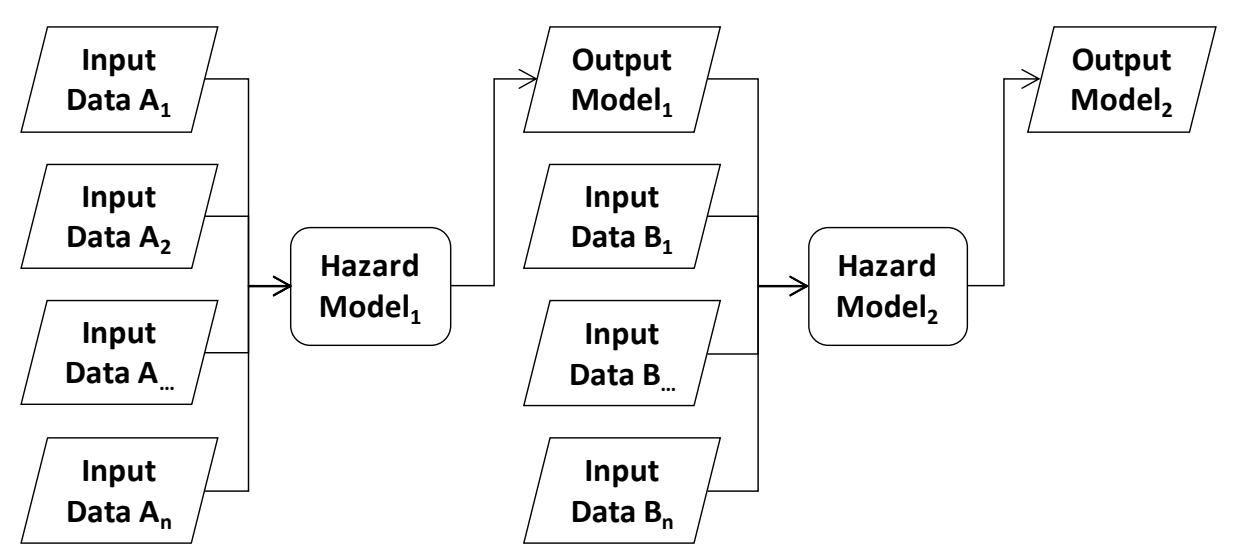

Figure 2. Scheme of loosely coupled model approach used for the multi-hazards assessment.

Floods analysis, treated through urban drainage, tidal and river flooding models, and a set of coupled models, was a common issue in the three RESCCUE sites, with flood resilience as one of their most critical concerns in a context of climate change. These models were developed, calibrated, and validated based on the available local data and software. The great differences among the main features of the RESCCUE models, in terms of intrinsic characteristics and accuracy of results, show the high replicability of the analysis carried out in other contexts with a wide range of resource availability.

Furthermore, for the case of Barcelona, also drought model and two water quality models have been developed. The former considered all the Llobregat-Ter rivers systems, while the later focused on the health and economic effects of Combined Sewer Overflows (CSOs) on bathing water during moderate and heavy storm events and on Llobregat river. That river is affected by high turbidity in case of high rainfall intensities producing erosion and the movement of the particles accumulated on the riverbed making the turbidity levels rise with serious problems for the Saint Joan Despí water treatment plant. The RESCCUE sectorial and coupled model are listed in Table 4.

Hundreds of simulations carried out by RESCCUE models were performed to achieve detailed and accurate multi-hazard assessment and cascading effects analysis for the different urban sectors analyzed in the three sites. These simulations were carried out considered the following scenarios:

- $\quad$ Baseline (or current scenario)

- Business as Usual scenario (BAU) according to the climate projections for a selected time horizon (generally 2100)

- Adaptation scenarios according to the selected adaptation strategies adopted by the three municipalities to face with climate change and to improve their resilience to extreme weather events. 
Table 4. Sectorial and coupled models used in RESCCUE project for the multi-hazard and multi-risk assessment.

\begin{tabular}{cccc}
\hline Sectorial and Coupled Models & Barcelona & Bristol & Lisbon \\
\hline Urban drainage model & $\checkmark$ & $\checkmark$ & $\checkmark$ \\
Flooding-transport model & $\checkmark$ & $\checkmark$ & $\checkmark$ \\
Flooding-electrical model & $\checkmark$ & $\checkmark$ & $\checkmark$ \\
Flooding—waste collection model & $\checkmark$ & $\checkmark$ & $\checkmark$ \\
Tidal-river flood model & & $\checkmark$ & $\checkmark$ \\
Sea level rise model & $\checkmark$ & & \\
Urban drainage-bathing water quality model & $\checkmark$ & & \\
Llobregat river water quality model & $\checkmark$ & & \\
Drought & $\checkmark$ & & \\
\hline
\end{tabular}

Results of hazard analysis were used to feed impacts models and to perform comprehensive risk assessment including tangible and intangible damages (socio-economic risk assessment). Moreover, the RESCCUE models were also used to evaluate hazard reduction produced by adaptation strategies implementation.

In terms of hazard analysis, for the case of Barcelona, the simulation results showed that climate change could significantly exacerbate flood hazard in the sectors of urban drainage, electricity, traffic and waste collection, while its effects on water quality (bathing water and river) seemed to be negligible $[11,13]$. Sea level rise analysis performed by GIS tools indicated moderate loss of beaches for the horizon of 2050 and 2100, although its effects should not affect critical infrastructures located in the vicinity of the coast. Drought analysis is in line with other recent studies related to the water availability for the city of Barcelona and predicts a $9 \%$ to $11 \%$ decrease in surface water volume availability over the reservoir system for the horizon of 2050 and 2100, respectively, due to precipitation reduction and warming-enhanced evaporation [12]. The simulations of adaptation measures considered the implementation of Sustainable Urban Drainage Systems (SUDS), resulting in high hazard reductions. Further implementation of structural measures could practically eliminate high flood hazard conditions for people and assets for low return periods (up to 10 years) [20].

For the case of Bristol, hazard assessment indicated that climate change could significantly increase hazard produced by tidal, river and pluvial floods. Bristol adaptation strategies to face pluvial flooding problem considered the implementation of different local adaptation measures (SUDS, increase of pipe and pumping capacity) to solve the most important problems in flood prone areas identified by simulations of Baseline and BAU scenarios $[14,20]$. For tidal and river flooding, adaptation measures limiting people and assets exposure were selected so no hazard assessment was performed in this case.

Finally, in Lisbon's case study, flood hazard assessment was performed using different urban drainage models (1D GIS sewer model for the whole area and 1D/2D sewer and overland coupled model for some catchments in the city center). 1D/2D combined model covers the flood prone areas identified in the simulations concerning Baseline and BAU scenarios. Coupled models for the cascading effects analysis crossed urban drainage outputs and GIS information regarding critical electrical, traffic and waste collection infrastructures. The climate change effects on urban drainage network and other services are quite limited. Notwithstanding, the implementation of SUDS and structural measures could improve significantly the hydraulic behavior of urban drainage systems with respect to Baseline and BAU scenarios. Exposure analysis of the combined effects of sea level rise and storm surges indicated potential effects on extended areas close to the coast.

\subsection{Impact Assessment Summary and Adaptation Strategies Identification for the Three Cities}

To reduce the level of risk and/or impact experienced by a critical service or infrastructure, a selected adaptation measure could be applied either as a means of reducing the severity of the hazard (Figure $3 \mathrm{~A}$ ) or by decreasing the vulnerability of the infrastructure or service accordingly (Figure 3B). 

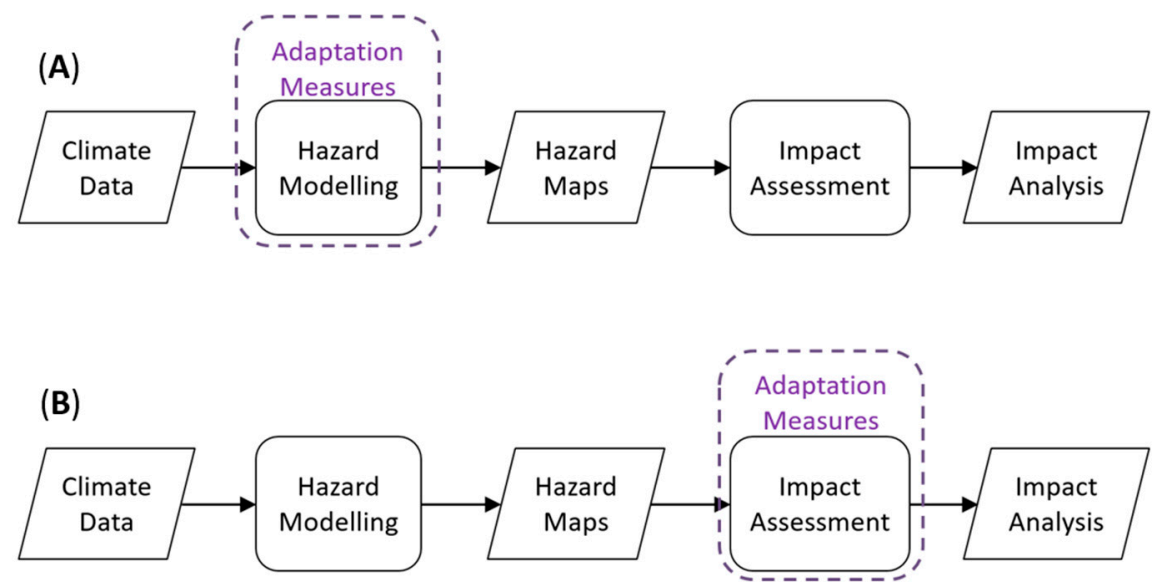

Figure 3. Adaptation measures applied to improve resilience of city either via hazard reduction (A) or vulnerability reduction $(\mathbf{B})$.

Due to the variability in data, models, resources, and specific interests, each city selected a range of critical services to analyze with respect to climate-driven impacts (Table 5) and evaluated the effectiveness of adaptation strategies that could help mitigate these impacts within their respective cities.

Table 5. Services selected for impact and adaptation measure assessment by respective cities.

\begin{tabular}{cccc}
\hline Impacted Service & Barcelona & Bristol & Lisbon \\
\hline Properties & $\checkmark$ & $\checkmark$ & $\checkmark$ \\
Vehicles & $\checkmark$ & & \\
Pedestrians & $\checkmark$ & & $\checkmark$ \\
Waste & $\checkmark$ & & $\checkmark$ \\
Energy & $\checkmark$ & $\checkmark$ & $\checkmark$ \\
Traffic/Transport & $\checkmark$ & $\checkmark$ & $\checkmark$ \\
CSOs & $\checkmark$ & $\checkmark$ & \\
Water Supply (Drought) & $\checkmark$ & & \\
\hline
\end{tabular}

In the Barcelona case study, the city investigated the combined use of Structural Measures (SM) and SUDS as a means of reducing the magnitude of potential flood hazards under future climate change conditions. The effectiveness of these measures was evaluated at a city scale and zonally across different census zones as shown in Figure 4.
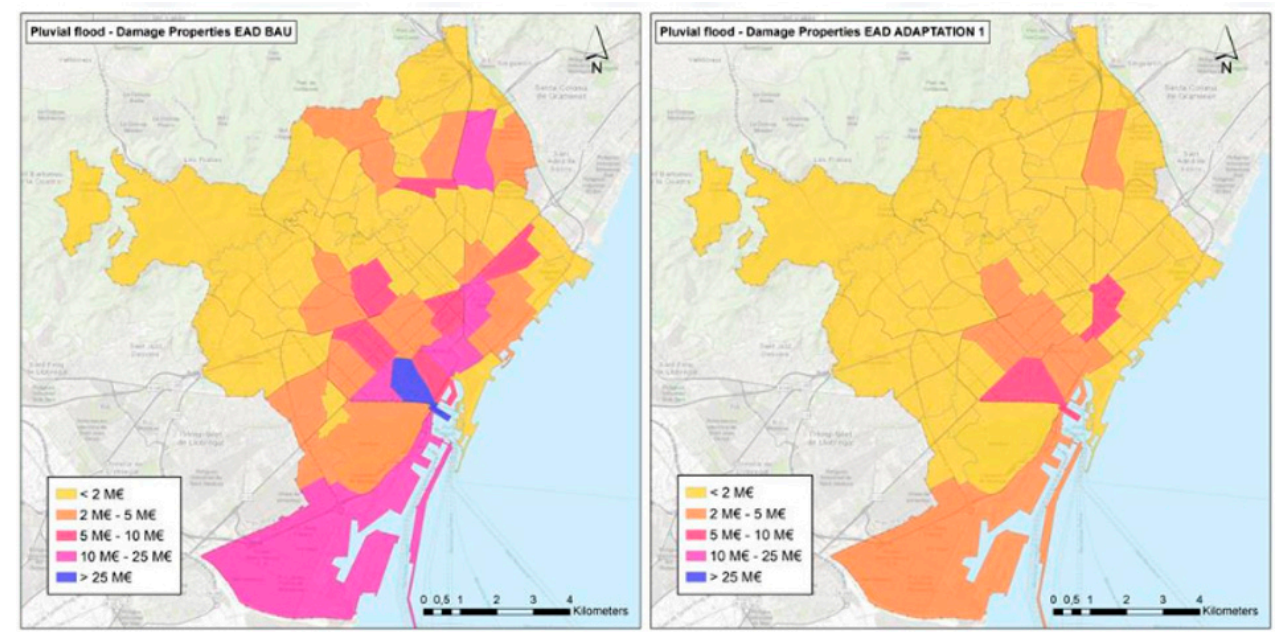

Figure 4. Different census zones used for the assessment of the effectiveness of adaptation measures. In this case, the implementation of SUDS (right) is compared to the Business as Usual situation (left). 


\subsubsection{Barcelona}

Outputs from 1D/2D flood model simulations where the adaptation measures have been applied (either to specific zones or a city-wide level) were compared to the Business As Usual (BAU) scenarios as a means of quantifying the effectiveness of the applied measures.

In the analysis for the reduction of impact to properties [21,22] and vehicles [23] combined, the use of SUDS citywide yielded a potential reduction in the expected annual damage (EAD) of $42 \%$, whereas a combination of SUDS and SM resulted in a potential reduction in EAD of up to $95 \%$. Additional analysis in the vehicular aspect revealed that the applied measures also provided benefits to the improvement of traffic flows during flooding events with an estimated $10 \%$ reduction in the average annual loss (AAL) [18].

Other approaches were used to assess direct risks posed to citizens by flooding [24]. Results showed that the use of SUDS and SM could range from a 99\% reduction of risks to pedestrians for a 10-year return period future climate change scenario to $59 \%$ reduction in risks for the most extreme 1-in-500-years scenario. Expanding on the use of stability-curve functions, the impacts of flood waters in their potential to dislodge waste containers were analyzed [16]. Within this example the application of fixing of waste containers to restrict their mobility in moving flood waters were included. The results showed that SUDS alone could provide a reduction in mobility by $20-30 \%$ for 50 - and 10 -year return periods respectively but by fixing of containers this could be improved greatly ranging from $80-100 \%$ reduction in their mobility.

The assessment of the electrical sector applied the use of fragility curves and a probabilistic GIS methodology to estimate potential disruption to power supplies [17]. Analysis of the System Average Interruption Frequency Index (SAIFI) that refers to the probability of experiencing a power outage revealed that SUDS alone could provide some benefits up to a 100-year return period but with the additional structural measures far greater reliability could be achieved.

For the reduction of impacts/risks that arise from CSO events Barcelona investigated the use of SUDS and retention tanks with their results showing that their uses were of more benefit in some regions than others.

In addition, Barcelona also explored potential measures to help adapt to future drought events and high turbidity events (Table 6). Analysis of these measures revealed that the adaptation scenario 3 (AS3) provides the most effective means of coping with these climate driven events.

Table 6. Proposed adaptation scenarios to deal with quality impacts on water resources.

\begin{tabular}{cl}
\hline Adaptation Scenario & \multicolumn{1}{c}{ Description } \\
\hline AS1 & Wastewater exploitation through regeneration processes \\
AS2 & Integrated use of groundwater, greywater, rainwater, and seawater, in conjunction \\
AS3 & with the optimization of the existing and planned aqueduct network \\
Water conveyance from another basin with higher water availability \\
\hline
\end{tabular}

\subsubsection{Bristol}

The city of Bristol investigated the use of adaptation strategies in two specific areas: Ashton Vale and the Centre of Bristol (focusing around the St Phillips Marsh region). Within the Ashton Vale area the city looked at measures that would reduce the magnitude of flood hazard through the combination of SUDS and improvements to existing drainage as a means of mitigating the effects of flooding and reducing the number of CSO events. Together, these measures could reduce the impermeable area draining to the combined sewer systems by $35 \%$ and the surface water system by $20 \%$. The analysis of the measures applied within RESCCUE show a potential reduction in CSO spill events per year of $18.75 \%$.

In contrast to the Ashton Vale region the analyses within the center of Bristol that investigated impacts to properties, traffic, and energy considered measures involving reducing the vulnerability of specific infrastructures. For buildings/properties the use of property level protection (PLP) was 
implemented. In this approach, the selection of properties that received PLP was based on evaluation of impacts from a 1-in-20-year BAU events. Two intervention placement methods within this study were investigated: Strategic intervention zones (Zonal selection) and individually targeted interventions (individual selection). The zonal approach utilizes an aggregated damage assessment overview to determine the top three locations (Super Output Areas) most at risk and count the number residential properties within these SOAs that will receive PLP. The individual zonal approach examines the individual properties across the city that are most at risk and a number of properties equal to that identified in the SOA approach will receive PLP respectively. The individual approach is therefore a more targeted approach. Within the top three SOAs with the most recorded damage 339 residential properties were identified. Each of these 339 properties in the zonal analysis were fitted with PLP to provide protection up to $600 \mathrm{~mm}$ in flood depths. For the individual analysis top individual 339 residential properties that recorded the highest damage were each fitted with PLP and damage impact assessments were carried out (Figure 5) with land-use classifications for Bristol, obtained via the National Receptor Dataset [25].

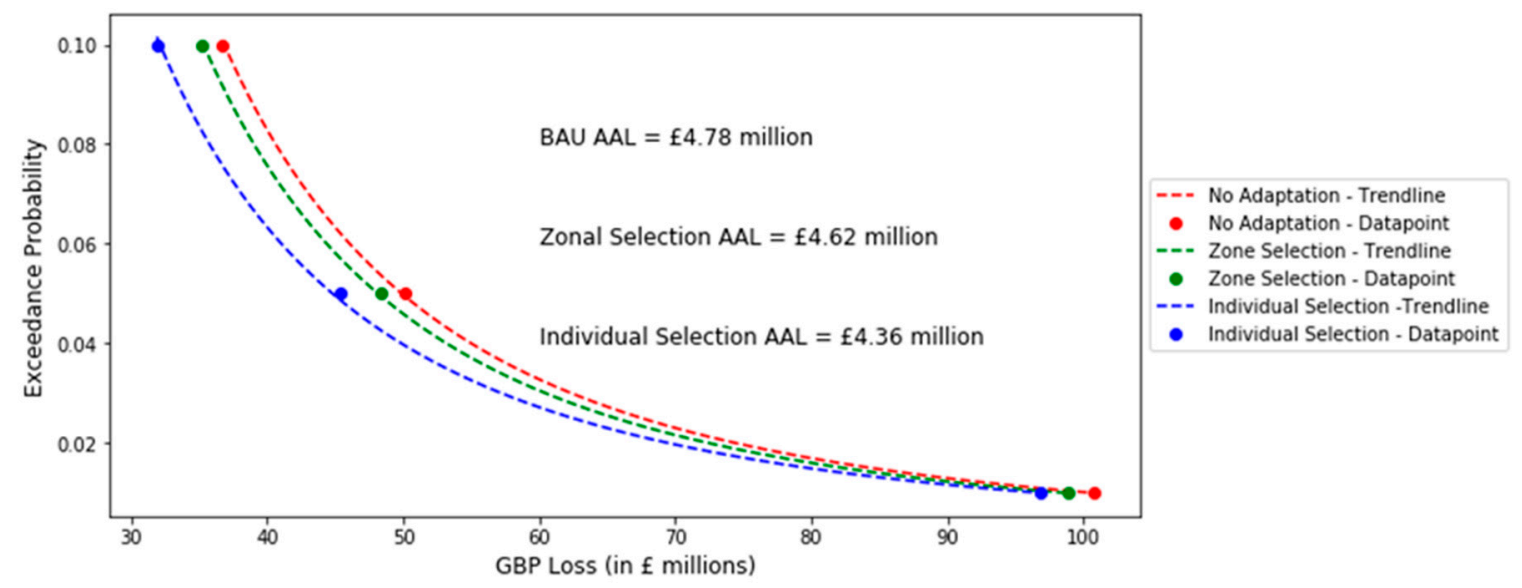

Figure 5. Average Annual Losses caused by pluvial flooding in 2115, assuming 'business as usual' practices compared against applied adaptation measures.

A PLP styled approach also investigated provision of protection to substations within the center of Bristol by localized flood barriers. These barriers would serve to remove the risk of flooding to infrastructures up to a threshold flood-depth. In this instance, the effectiveness of barriers was analyzed in terms of probability of disruption of supply to customers when applying barriers to substations with different calculated levels of Water Depth Hazard, having slight improvements when applying barriers to substations with WDH greater than 1, and considerable improvements when applying barriers to all substations with WDH greater than 0.5 (Figure 6). Additionally, a sensitivity analysis of the cost of implementing flood barriers was carried out.

For the traffic modelling, a simplified approach was adopted whereby key roads/bridges within the city were assumed to be protected and clear of flood water during flood events. A comparison of BAU flooding for pluvial events scenario was then carried out with these key road sections (protected vs. unprotected from flooding). These results highlighted the potential importance of keeping these roads clear of flood water with a $35 \%$ reduction in recovery for a 1-in-10-years event under future climate change scenarios. 


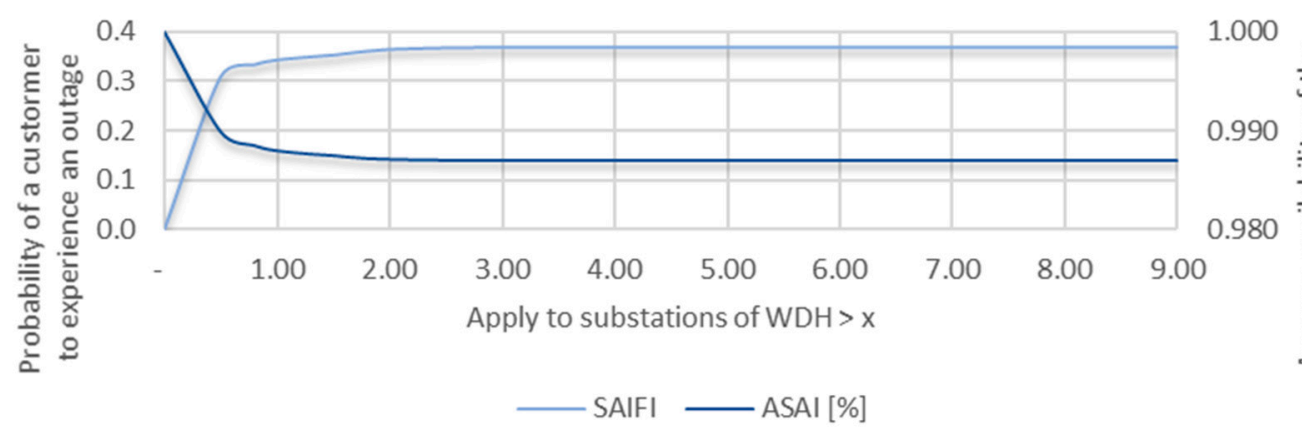

Figure 6. System Average Interruption Frequency Index (SAIFI) and ASAI (Average System Availability Index) reliability indices calculated for a Business as Usual (BAU) scenario using SWMP (Storm Water Management Program) hydraulic model with return period T1000 for a range of WDH from 0 to 9 in Bristol.

\subsubsection{Lisbon}

Several adaptation strategies and measures were identified as having potential for improving adaptation to climate change scenarios related to flooding in Lisbon. Limitations on available information and tools determined that detailed assessment of exposure and consequences was viable only for two downtown catchments. For the Lisbon case study, with respect to mitigating the impacts of flooding on buildings, the city looked to investigate Climate Adaptation Strategy 3 (AS3) which comprised of the measures outlined in Table 7.

Table 7. Adaptations measures that comprise Climate Adaptation Strategy 3 (AS3).

\begin{tabular}{cc}
\hline Measure ID & Description \\
\hline M016FLOOD & Rehabilitate sewer pipes \\
M017FLOOD & Inlets Increase \\
M023FLOOD & Construction of diversion tunnels \\
M027FLOOD & Construction of anti-pollution basins \\
\hline
\end{tabular}

For the impact assessments, Lisbon applied the depth-damage curves for associated land-use classification used within the Barcelona case study and analyzed the respective damages for the current day scenario (CS), Business as Usual (BAU) future climate change scenarios where no adaptation measures have been applied and Climate Adaptation Strategy 3 whereby the measures outlined in Table 8 have been applied to mitigate the effects of flooding from BAU flood model outputs.

Table 8. Lisbon downtown: buildings exposure to flooding hazards (CS, BAU, and AS3).

\begin{tabular}{ccccccc}
\hline Scenario & Return Period & $\mathbf{0 . 2 - 0 . 4}$ & $\mathbf{0 . 4 - 0 . 6}$ & $\mathbf{0 . 6 - 0 . 8}$ & $\mathbf{0 . 8 - 1 . 0}$ & Total \\
\hline \multirow{2}{*}{ CS } & 1 in 10 & $13,186,596$ & $17,927,820$ & $4,681,748$ & $6,029,586$ & $41,825,750$ \\
& 1 in 20 & $13,646,385$ & $17,133,464$ & $4,380,333$ & $8,469,564$ & $43,629,746$ \\
& 1 in 100 & $11,081,863$ & $21,700,791$ & $5,147,006$ & $5,050,583$ & $42,980,243$ \\
\hline \multirow{2}{*}{ BAU } & 1 in 10 & $14,073,467$ & $14,529,768$ & $5,866,800$ & $8,519,502$ & $42,989,537$ \\
& 1 in 20 & $12,563,304$ & $17,809,371$ & $4,946,306$ & $9,634,345$ & $44,953,326$ \\
& 1 in 100 & $12,120,733$ & $20,206,950$ & $8,247,047$ & $8,482,180$ & $49,056,910$ \\
\hline \multirow{2}{*}{ AS3 } & 1 in 10 & $11,521,261$ & $16,204,992$ & $3,359,126$ & $5,103,920$ & $36,189,299$ \\
& 1 in 20 & $11,602,000$ & $18,521,844$ & $5,837,237$ & $9,786,510$ & $45,747,591$ \\
& 1 in 100 & $11,990,516$ & $20,590,989$ & $7,685,365$ & $5,648,679$ & $45,915,549$ \\
\hline
\end{tabular}


Within the transportation network Lisbon examined the risks posed to pedestrians and vehicles to flood waters. Their results showed that the application of measures outlined in AS3 can help mitigate the risks posed to commuters within the city of Lisbon (Table 9).

Table 9. Lisbon downtown: exposure of pedestrians to flooding related hazard as percentage of total area increase compared to CS (whole catchment).

\begin{tabular}{ccccccc}
\hline & \multicolumn{2}{c}{ T010 } & \multicolumn{2}{c}{ T020 } & \multicolumn{2}{c}{ T100 } \\
\hline Risk & BAU & AS3 & BAU & AS3 & BAU & AS3 \\
\hline Low & $-4.1 \%$ & $-1.0 \%$ & $-3.6 \%$ & $-1.3 \%$ & $-2.9 \%$ & $+3.0 \%$ \\
Moderate & $+3.2 \%$ & $+1.0 \%$ & $-2.6 \%$ & $+1.0 \%$ & $+2.0 \%$ & $-1.6 \%$ \\
Significant & $+0.8 \%$ & $0.0 \%$ & $+0.9 \%$ & $+0.3 \%$ & $+0.8 \%$ & $-1.3 \%$ \\
Extreme & $+0.0 \%$ & $0.0 \%$ & $0.0 \%$ & $0.0 \%$ & $0.0 \%$ & $0.0 \%$ \\
\hline
\end{tabular}

The analysis of traffic speeds within the network (based on flood-depth exposure along road surfaces) showed a $27 \%$ reduction in the length of roads limiting the maximum speed of vehicles to $10 \mathrm{~km} / \mathrm{h}$ for a 1 in 10 year event whilst AS3 are implemented and a $42 \%$ reduction in the length of roads where the flood-depths would be unsurpassable to traffic for a 1 in 10 year future event.

Differing from that of the Barcelona case study, the impact assessment on waste within Lisbon considered the potential impact of flood waters on waste containers used by residents within the city that are placed outside their properties for periodic collection. The exposure of the waste containers is relatively low and although AS3 measures provide some benefit, the exposure level is similar to that of the BAU scenario.

The infrastructure for supplying energy within the city of Lisbon is highly robust with a high degree of redundancy. This means that the grid has incremental layers of resilience that serve to minimize the likelihood of disruption. Hazard assessments have identified substations that may be exposed to flooding and sea-level rise. The configuration of the network, however, means that if the potentially exposed substations were to fail, the network has redundancies in place to switch to ensure power distribution is maintained.

\section{Prioritization of Adaptation Strategies for the Three Cities}

The implementation of adaptation strategies is normally limited by factors such as capital and labor constraints and subject to political momentum; therefore, a prioritization assessment should be performed in order to select the most suitable set of measures for each city under a changing climate scenario [20]. There are multiple criteria to rank available options to facilitate decision-making processes. The preferred methods usually imply consideration of efficiency, economic, social and environmental indicators.

A sensible approach begins by recognising that there are several viable strategies with different contributions to society, thus there are multiple combinations for effective adaptation. Some of them will be more efficient minimizing the risks associated to social issues (e.g., protect the most vulnerable people), while others will cover those related to urban services (e.g., secure electricity supply). It is also relevant to address the variety of information available for every strategy and measure, as well as the effects of those in society and the economy.

In RESCCUE project, a flexible approach has been proposed to prioritise adaptation measures, to be adaptable to a variety or urban environments. A twofold level of detail was considered in its development, due to variability of data available. It followed mainly the principles of a Multicriteria Analysis (MCA):

- Gives relevance to stakeholder decisions

- Uses normalized quantitative and qualitative indicators through a scoring system

- Can rank options with different goals 
- Offers a multi-phase analysis approach

Combinations of assessment methods form its process, which are ordered from more basic to more detailed. The initial phase includes a Cost-Efficiency Analysis (CEA) and co-benefits scoring assessment, related to the adaptation options. The second stage considers a more detailed appraisal, by encompassing, among others, risks reduction assessments and Costs-Benefit Analysis (CBA). The goal of the prioritization methodology is to rank adaptation measures for the decision-makers to select the most suitable ones for their specific local policy goals. This methodology is described in depth in the work presented in [20]. Figure 7, however, presents an introductory diagram of it.

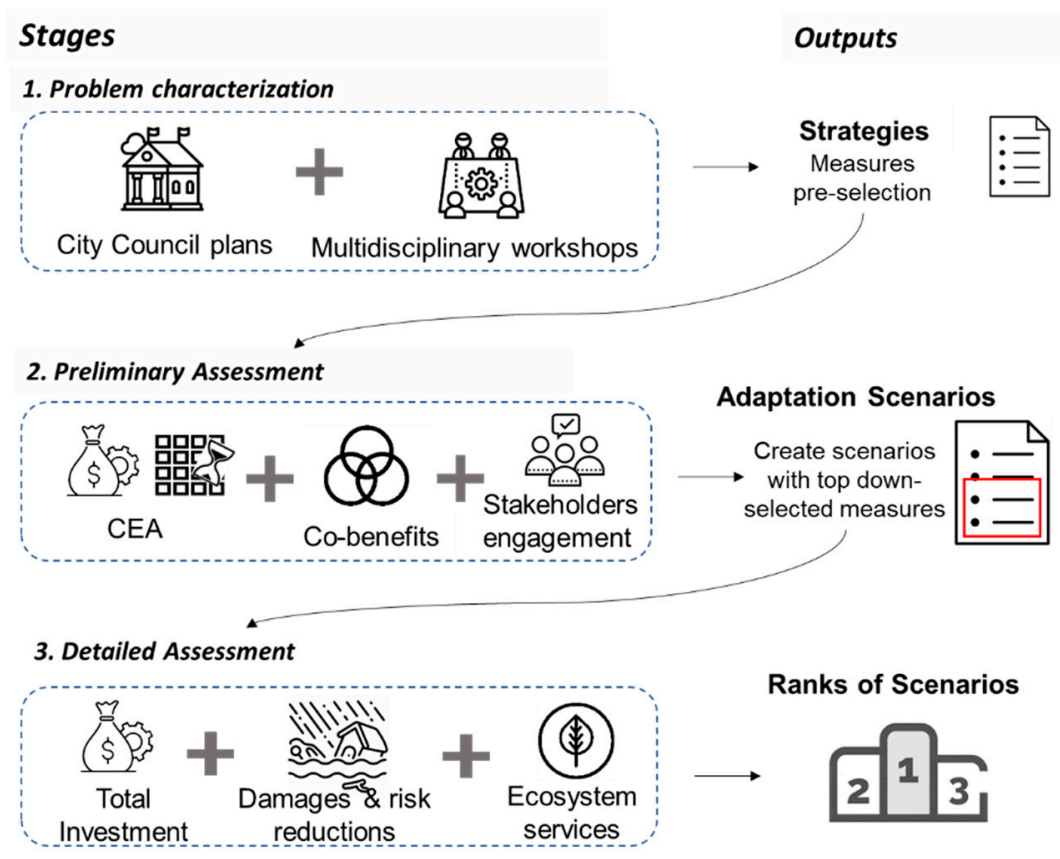

Figure 7. Outline of the methodology stages and outputs [20].

This methodology was applied to the cities of Barcelona and Bristol. Based on the existing Climate Plans of the cities and the workshops with stakeholders, 4 strategies and 27 measures were proposed for Barcelona, and 3 strategies and 14 measures for Bristol. For Barcelona, the prioritization method was applied to those related to pluvial flooding and CSO spills. Stakeholders decided to focus on the improvement of Bristol's resilience against pluvial and fluvial flooding events and CSO spills (Table 10).

Results from the preliminary assessment provide stakeholders with an insight about how efficient the single effect of each adaptation measure can be. This first rank is a starting point for decision-makers to create adaptation scenarios (i.e., subsets of measures within a strategy) whose effectiveness can be assessed in the step of the proposed methodology. Results regarding this preliminary assessment are presented in Table 11 for the case study of Bristol. 
Table 10. Description of selected strategies and their measures to be prioritized in the two case studies [20].

\begin{tabular}{|c|c|}
\hline Case Study & Selected Strategies and Their Measures \\
\hline \multirow{14}{*}{ Barcelona } & Pluvial flooding \\
\hline & Improvements of surface drainage system \\
\hline & Increase of sewer system capacity-New pipes (I) \\
\hline & 3. Increase of sewer system capacity-New detention tanks (II) \\
\hline & $\begin{array}{l}\text { 4. SUDS scheme (increased area of green roofs, infiltration trenches, } \\
\text { and detention basins) }\end{array}$ \\
\hline & 5. Early Warning System \\
\hline & Self-healing algorithm implemented in the electrical distribution grid \\
\hline & 7. Ensure the stability of waste containers \\
\hline & Combined sewer overflows (CSO) spills \\
\hline & 1. SUDS scheme \\
\hline & 2. $\quad$ Early Warning System (EWS) \\
\hline & 3. Detention tanks for CSO prevention \\
\hline & 4. Improvements of the capacity of sewer interceptor and WWTP \\
\hline & 5. End of pipe CSO treatment \\
\hline \multirow{14}{*}{ Bristol } & Pluvial flooding Fluvial flooding \\
\hline & 1. Flood proof crucial infrastructures \\
\hline & 2. Build riverside flood defense walls \\
\hline & 3. Demountable flood protection barriers \\
\hline & $\begin{array}{l}\text { 4. Identify high-risk areas by conducting studies involving flood } \\
\text { modelling analysis }\end{array}$ \\
\hline & CSO events (in the Ashton Vale area) ${ }^{1}$ \\
\hline & 1. Inlet diameters increase \\
\hline & 2. Disconnecting paved surfaces from the combined system \\
\hline & 3. Full surface water separation \\
\hline & $\begin{array}{l}\text { 4. SUDS scheme (swales, filter trenches, permeable paving, detention basins, } \\
\text { mixed schemes) }\end{array}$ \\
\hline & 5. Raising curb heights \\
\hline & 6. Increasing surface water sewer system capacity \\
\hline & 7. Tide isolation of drainage systems \\
\hline & 8. Improvements to watercourse capacities \\
\hline
\end{tabular}

${ }^{1} \mathrm{CSO}$ events strategy is presented in Appendix B, because it was assessed in only one area of the city and thus not comparable with the other two strategies embracing the entire city.

Table 11. Preliminary ranking results for the adaptation measures included in the pluvial and fluvial strategies within the central area of Bristol.

\begin{tabular}{cccccc}
\hline & Weights Given & $\mathbf{2 5 \%}$ & $\mathbf{2 5 \%}$ & $\mathbf{2 5 \%}$ & $\mathbf{2 5 \%}$ \\
\hline Rank & $\begin{array}{c}\text { Pluvial Flood } \\
\text { Strategy Measures }\end{array}$ & CEA ( $/ \mathbf{h})$ & Economic & Social & Environmental \\
\hline 1 & $\begin{array}{c}\text { Demountable flood } \\
\text { protection barriers }\end{array}$ & $\mathbf{7 2 4 3}$ & $39 \%$ & $81 \%$ & $\mathbf{3 9 \%}$ \\
\hline 2 & $\begin{array}{c}\text { Identify high-risk areas (flood } \\
\text { modeling analysis studies) }\end{array}$ & 60,790 & $23 \%$ & $57 \%$ & $14 \%$ \\
\hline 3 & $\begin{array}{c}\text { Flood proof crucial } \\
\text { infrastructures }\end{array}$ & 134,608 & $7 \%$ & $3 \%$ & $14 \%$ \\
\hline
\end{tabular}


Table 11. Cont.

\begin{tabular}{cccccc}
\hline Rank & Weights Given & $\mathbf{2 5 \%}$ & $\mathbf{2 5 \%}$ & $\mathbf{2 5 \%}$ & $\mathbf{2 5 \%}$ \\
\hline 1 & $\begin{array}{c}\text { Fluvial/Tidal Flood } \\
\text { Strategy Measures }\end{array}$ & CEA ( $/ \mathbf{h})$ & Economic & Social & Environmental \\
\hline 2 & $\begin{array}{c}\text { Demountable flood } \\
\text { protection barriers }\end{array}$ & 8450 & $39 \%$ & $81 \%$ & $39 \%$ \\
\hline 3 & $\begin{array}{c}\text { Build riverside flood } \\
\text { defense walls }\end{array}$ & $3,749,280$ & $64 \%$ & $87 \%$ & $41 \%$ \\
\hline 4 & $\begin{array}{c}\text { Identify high-risk areas by } \\
\text { conducting studies involving } \\
\text { flood modeling analysis }\end{array}$ & 56,509 & $23 \%$ & $57 \%$ & $14 \%$ \\
\hline
\end{tabular}

The aim of this detailed assessment was to provide as much information as possible to solve the concerns of decision-makers regarding the different aspects of the policy making process, i.e., budgetary, welfare, and risks.

As an example of application of this detailed assessment, in the Bristol case study, stakeholders were interested in the potential impacts of different intensities events for two scenarios and to compare them to the BAU scenario (Table 12). These were ranked based on the total damage costs expected during a range of extreme flood events in the city. The assessment was calculated by developing a baseline of expected flood damages during a flood event in the future and comparing them to the expected flood damages with property-level protection applied to targeting buildings or strategic zones (Table 13).

Table 12. Adaptation scenarios for each strategy in Bristol case study.

\begin{tabular}{cll}
\hline Strategy Name & & \multicolumn{2}{c}{ Adaptation Scenarios (AS) } \\
\hline \multirow{3}{*}{ Pluvial flooding impacts reduction } & 1. & Pluvial_AS1. BAU with climate change \\
& 2. & Pluvial_AS2. BAU CC with zonally targeted interventions \\
& 3. & Pluvial_AS3. BAU CC with individually targeted interventions \\
\hline \multirow{3}{*}{ Fluvial flooding impacts reduction } & 1. & Fluvial_AS1. BAU with climate change \\
& 2. & Fluvial_AS2. BAU CC with zonally targeted interventions \\
& 3. & Fluvial_AS3. BAU CC with individually targeted interventions \\
\hline
\end{tabular}

Table 13. Estimated total flood damages resulting from extreme pluvial flood events to all building classes for different return periods (Tyears) $(£)$ in Bristol.

\begin{tabular}{cccccc}
\hline Rank & Scenarios & T10 & T20 & T30 & T100 \\
\hline 1 & $\begin{array}{c}\text { BAU CC with individually } \\
\text { targeted interventions }\end{array}$ & $31,880,000$ & $45,322,000$ & - & $96,796,000$ \\
\hline 2 & $\begin{array}{c}\text { BAU CC with zonally } \\
\text { targeted interventions }\end{array}$ & $35,218,000$ & $48,312,000$ & - & $98,804,000$ \\
\hline 3 & $\begin{array}{c}\text { Business as Usual, considering } \\
\text { climate change impact (BAU-CC) }\end{array}$ & $36,692,000$ & $50,088,000$ & - & $100,757,000$ \\
\hline
\end{tabular}

Within this methodology it is acknowledged that the aim of researchers is not selecting the "best" adaptation options, but to provide a picture of how effective these options can be under certain criteria. Therefore, the prioritization results are a starting point for city planners to take better-informed decisions. A joint assessment of technical, socio-economic, and environmental aspects provides added value to policy makers, compared to those single-feature assessments. That was the focus of the present methodology, the application results of which are expected to lead to informed decisions regarding adaptation to climate change in urban areas. 


\section{Planning for Resilience}

Development of a Resilience Action Plan (RAP) is an important process for any city to plan resilience enhancement considering the long term. A RAP is a key tool for the city, considering the associated complexity, uncertainties, data scarcity, interdependencies among urban services provided in the city, as well as involved stakeholders. The RAP provides a roadmap for resilience, defining a path to enhance resilience of the city and its services regarding climate change, with focus on the urban water cycle. It is based on the intense work and background already existing in the city, the establishment of climate change planning scenarios, the characterization of the city context and hazards, the risk and resilience assessment and on the development of the strategies that need to be implemented to enhance the resilience of the city to climate change with focus on water. The RAPs developed for Barcelona, Bristol, and Lisbon are thematic plans contributing to the cities' global planning and followed the defined planning process presented in Figure 8 [26]. Urban services addressed are water supply, wastewater, storm water, waste, electric energy, and mobility. In each step approaches and tools were developed and applied. A synthesis of the three RAPs' results is presented in Table 14.

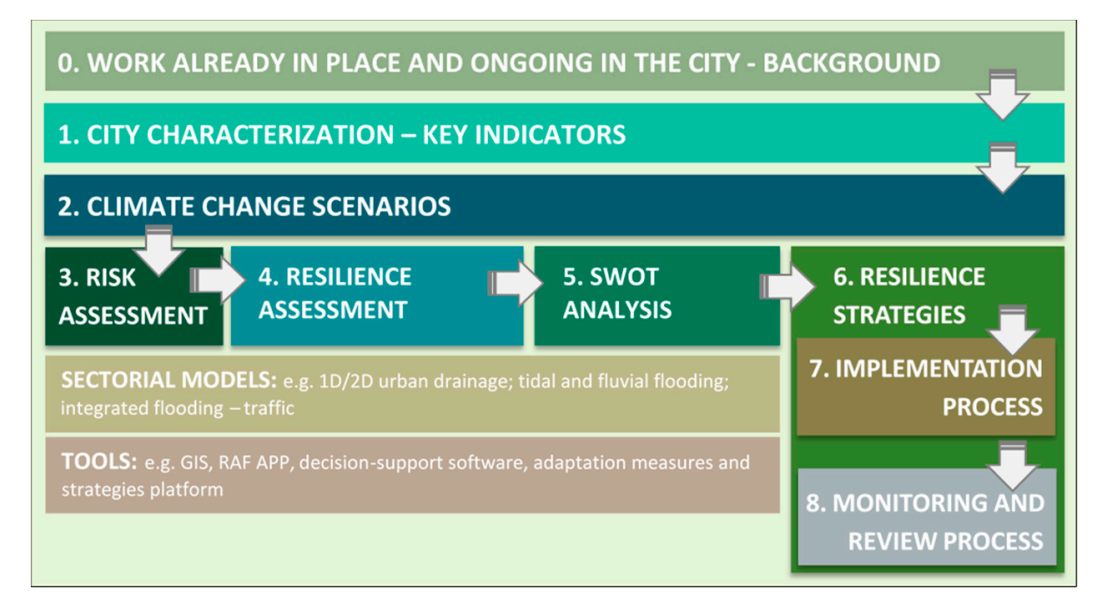

Figure 8. Planning process to develop a Resilience Action Plan [26].

The RAP is intended to be concise and it is targeted to a broad audience that includes experts and the general public. Therefore, the methods applied, both developed within the RESCCUE project or that already existed in the cities, are therein referred to or cited, since they make part of the planning process, but they are not detailed in the plans. 
Table 14. Barcelona, Bristol, and Lisbon Resilience Action Plans synthesis [27-35].

\begin{tabular}{|c|c|c|c|}
\hline & Barcelona & Bristol & Lisbon \\
\hline Characterization and background & 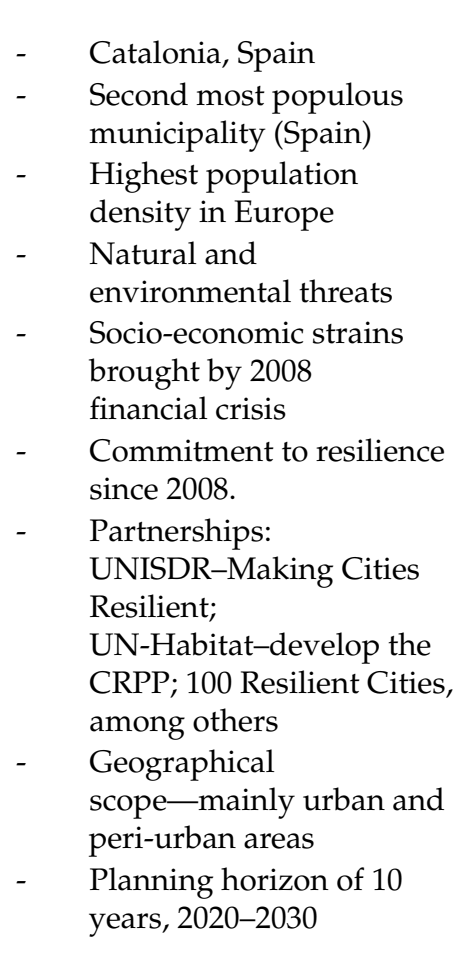 & $\begin{array}{ll}\text { - } & \text { South-west England } \\
\text { - } & \text { Second largest city in the } \\
\text { southern region, } \\
\text { after London } \\
\text { - } \quad \begin{array}{l}\text { One of the most densely } \\
\text { populated parts of the UK }\end{array} \\
\text { - } \quad \text { High-risk flooding areas } \\
\text { - } \quad \text { Bristol Green Capital } \\
\text { Partnership (2014); Core } \\
\text { City UK; ICLEI; 100 } \\
\text { Resilient Cities; 2019 One } \\
\text { City Plan } \\
\text { Implemented Ashton } \\
\text { strategy of identification } \\
\text { of high-risk areas by } \\
\text { conducting studies } \\
\text { involving } \\
\text { flood-modelling analysis } \\
\text { Geographical } \\
\text { scope-Bristol City } \\
\text { Council administrative } \\
\text { and metropolitan area } \\
\text { Planning horizon of five } \\
\text { years, 2020-2025 }\end{array}$ & $\begin{array}{l}\text { - Portugal's largest } \\
\text { urban expanse } \\
\text { More than } 1.0 \text { million citizens } \\
\text { living, working, studying, } \\
\text { circulating and visiting } \\
\text { the city } \\
\text { Metropolitan area with } 2.8 \\
\text { million inhabitants } \\
\text { Contextual environmental } \\
\text { threats and contingent } \\
\text { impacts of CC as } \\
\text { major vulnerability } \\
\text { International partnerships: } \\
\text { UNISDR-Making Cities } \\
\text { Resilient; } 100 \text { Resilient Cities; } \\
\text { C40 Cities Network } \\
\text { Strategic and action plans, } \\
\text { e.g., Municipal Master Plan } \\
\text { and Municipal Strategy for } \\
\text { Climate Change Adaptation } \\
\text { Geographical scope-city } \\
\text { boundaries, mainly } \\
\text { urban area } \\
\text { Planning horizon of } 10 \\
\text { years, 2020-2030 }\end{array}$ \\
\hline
\end{tabular}


Table 14. Cont.

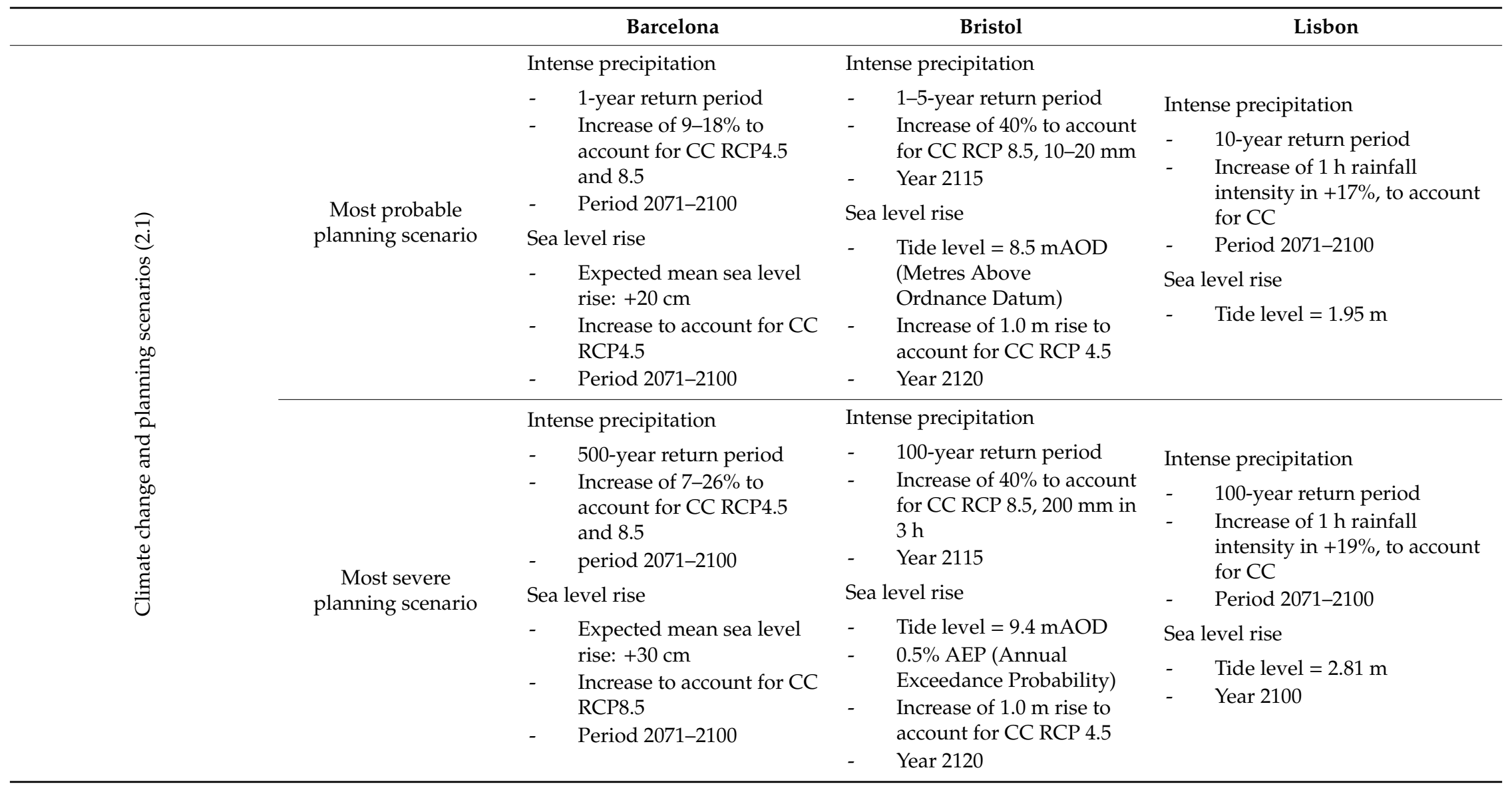


Table 14. Cont.

\begin{tabular}{|c|c|c|c|}
\hline & Barcelona & Bristol & Lisbon \\
\hline $\begin{array}{l}\text { Hazard and impact } \\
\text { assessment: } \\
\text { illustrative results }\end{array}$ & $\begin{array}{l}\text { Flood|risk reduction expected } \\
\text { - } \quad 99 \% \text { (T10) and 59\% (T500) } \\
\text { for pedestrians } \\
\text { 99\% (T10) and 66\% (T500) } \\
\text { for vehicles } \\
\text { 95\% Expected Annual } \\
\text { Damage (properties } \\
\text { and vehicles) }\end{array}$ & $\begin{array}{l}\text { CSO|reduction expected } \\
\text { - } \quad \text { spill events per year of } \\
\quad \begin{array}{l}18.75 \% \\
\text { - } \quad \text { volume reduction of } 18.7 \%\end{array}\end{array}$ & $\begin{array}{l}\text { Flood|risk reduction expected } \\
\text { - } \quad \text { 13\% (T10) and 19\% (T100) } \\
\text { for buildings } \\
\text { 13\% (T10) and } 11 \%(\mathrm{~T} 100) \\
\quad \text { for residents } \\
\text { 70\% (T10) and } 44 \%(\mathrm{~T} 100) \\
\quad \text { for roads }\end{array}$ \\
\hline \multicolumn{4}{|l|}{ Resilience Assessment (RAF) [36] } \\
\hline $\begin{array}{l}\text { Planned strategies and impact on the } \\
\text { resilience assessment (3) }\end{array}$ & $\begin{array}{l}\text { (a) Non-structural and } \\
\text { Nature Based Solutions to } \\
\text { reduce the impacts of } \\
\text { flooding events } \\
\text { (b) Improve the receiving } \\
\text { water bodies } \\
\text { (c) Use alternative water } \\
\text { resources to increase } \\
\text { water availability } \\
\text { (d) Guarantee security of } \\
\text { services provision }\end{array}$ & $\begin{array}{l}\text { (e) } \begin{array}{l}\text { Develop community } \\
\text { flood plans }\end{array} \\
\text { (f) } \begin{array}{l}\text { Keep identification of } \\
\text { high-risk areas updated } \\
\text { by conducting studies } \\
\text { involving } \\
\text { flood-modelling analysis }\end{array} \\
\text { (g) } \begin{array}{l}\text { Build riverside flood } \\
\text { defense walls }\end{array} \\
\text { (h) } \begin{array}{l}\text { Reduce surface water } \\
\text { runoff and sewer overload } \\
\text { by adding raingardens } \\
\text { before sewer inlets }\end{array}\end{array}$ & $\begin{array}{ll}\text { (i) } & \begin{array}{l}\text { Adaptation of } \\
\text { green infrastructure }\end{array} \\
\text { (j) } & \begin{array}{l}\text { Promoting urban } \\
\text { rehabilitation as a tool to } \\
\text { increase resilience: sewer } \\
\text { systems and facing } \\
\text { climate change }\end{array} \\
\text { (k) } & \begin{array}{l}\text { Construction of new } \\
\text { components in } \\
\text { drainage system }\end{array} \\
\text { (l) } & \begin{array}{l}\text { Strengthening collaboration } \\
\text { within AML, parishes, and }\end{array} \\
\text { municipality departments } & \text { Lisbon urban drainage } \\
\text { (m) } & \begin{array}{l}\text { monitoring and } \\
\text { early-warning system } \\
\text { Building protections for urban } \\
\text { electrical infrastructure, } \\
\text { exposed to estuarine flood }\end{array}\end{array}$ \\
\hline & $\begin{array}{l}\text { Globally, the set of plann } \\
\text { services considered in the }\end{array}$ & $\begin{array}{l}\text { trategies in each city address a } \\
\text { ins. }\end{array}$ & resilience dimensions as well as all \\
\hline
\end{tabular}


Table 14. Cont.

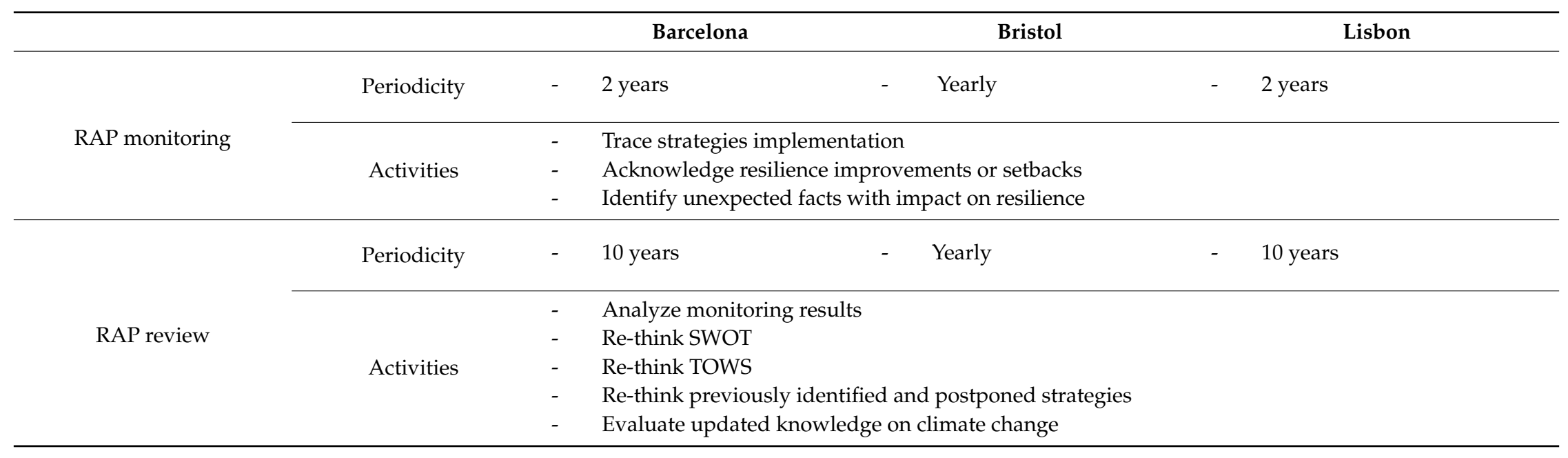


The production of the plans by each RESCCUE city was based in a template with detailed guidelines (Figure 9), developed as a supporting tool within RESCCUE. This application provided opportunities to produce a general template and respective guidelines that can be used by any city to develop its own RAP to climate change.
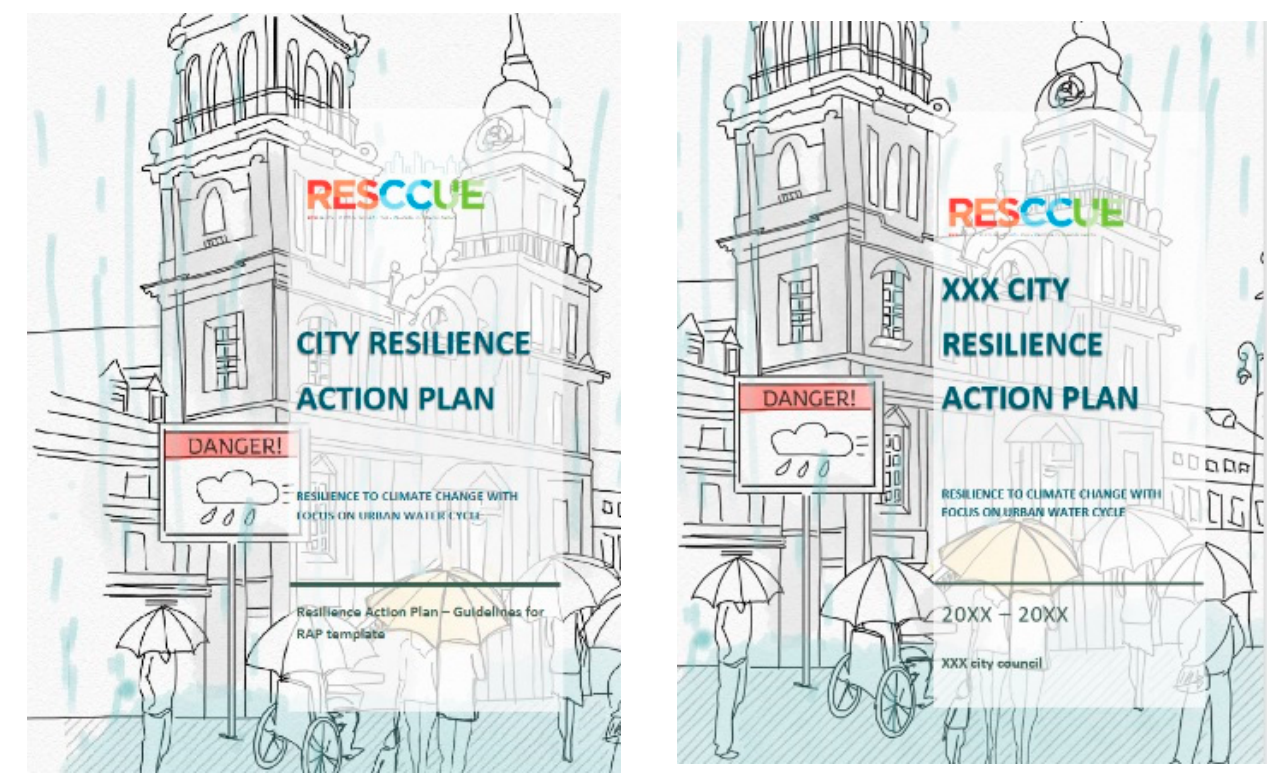

Figure 9. RAP template and guidelines [26].

The template is structured in 7 sections. The first introductory section provides the city background, an overview of the plan scope, focus, time horizon, planning process and structure. In Section 2, a brief characterization of the city and of the addressed urban services is provided, focusing on the plan scope. In Section 3, the climate change scenarios considered for the city in this plan are briefly presented, as well as the related hazards, risks, and vulnerabilities. The resilience assessment and a SWOT analysis are presented in Section 4, followed by the description and planning of the adaptation strategies selected, in Section 5. In Section 6, steps for plan monitoring and review are acknowledged and scheduled. Chapter 7 presents the final remarks of the plan, with a brief list of identified benefits and future challenges, as well as any relevant acknowledgments.

The guidelines present suggestions of text to be included in each section of the RAP, along with examples for a fictional RESCCUE City, to be adapted by the cities. Additional guidance is also provided, to support the city on the expected depth of analysis in each section.

The city may complete or adapt the template suggestions to fit better its own context and expectations for the RAP. For the cities that already have their city RAP (either general or specific) or a Resilience Strategy in place, an option is to include in those documents only some sections of this template.

\section{RESCCUE Dissemination Tools}

Research and innovation cannot be conceived without communication. Throughout the project's lifetime, RESCCUE has placed much effort on dissemination tasks, aiming at allowing general and specialized audiences to access information about the project progress and its outcomes. Besides, during the last stages of the project, the main objective in terms of communication and dissemination has been the promotion of the widest application of the RESCCUE tools and methodologies in other cities. In this regard, the RESCCUE Guidelines and the RESCCUE Toolkit are key to meet this goal. 


\subsection{RESCCUE Guidelines: How to Summarise the Know-How of the Project in a Few Pages}

Several guidelines on the different RESCCUE Work Packages (WP) have been developed aiming at providing the end-users with its most relevant outputs. These materials, which are available both printed and online, synthesize the key outputs of each stage of the project in an attractive and easy-to-understand format and serve to present a roadmap on how to apply the RESCCUE methodology in different cities (Figure 10). The pack of 6 guidelines is described below.

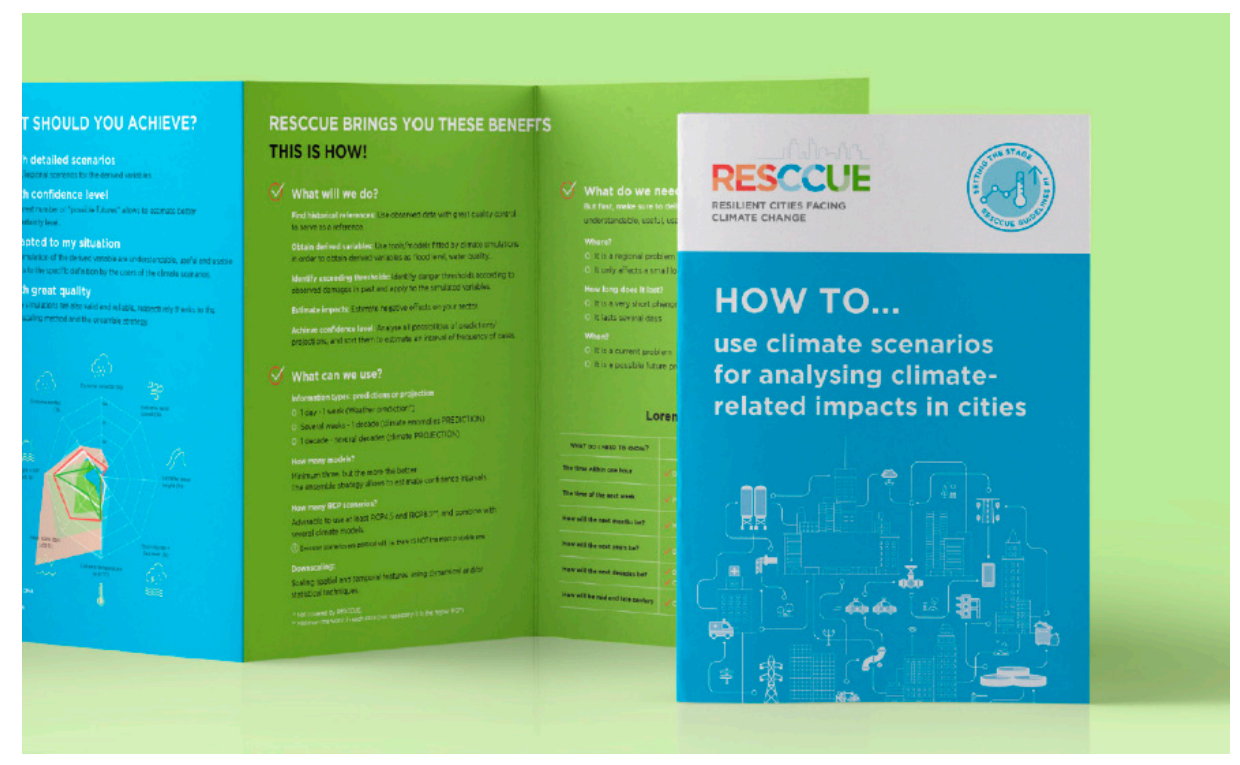

Figure 10. Example of the printed version of RESCCUE WP1 guidelines.

1. How to use climate scenarios for analyzing climate-related impacts in cities: The creation of climate change scenarios, according to different climate variables, facilitates the implementation of adaptation measures as well as reduces the level of uncertainly.

2. How to analyze the behavior of critical urban services under climate pressures: Testing different methodologies in order to develop multiple hazard assessment for strategic urban services and infrastructure provides deep knowledge about the behavior of urban services under extreme climate conditions.

3. How to estimate direct, indirect, and subsequent cascading impacts from climate driven hazards: The failure of services due to climate driven hazards may trigger further impacts and disruptions to other services, known as cascading effects. Within RESCCUE, the potential impacts on critical infrastructures and services as a result of climate driven hazards were selected to be assessed in the cities of Barcelona, Bristol, and Lisbon for both current and future climate scenarios.

4. How to globally analyze, diagnose and manage urban resilience with a holistic approach: With a holistic resilience approach, the city vulnerabilities can be identified, together with its critical infrastructures and key relationships among critical services, allowing to understand the existing interdependences.

5. How to effectively prioritize adaptation strategies to enhance urban resilience: Cities must adapt to increasing climate impacts, by setting an adaptation strategy based on the context, on its resources and necessities, of each city.

6. How to develop and implement a Resilience Action Plan (RAP) in your city: Water-related risks may be aggravated by climate change and eventually condition the correct functioning of the city. The Resilience Action Plan finds the best responses for those gaps. 


\subsection{RESCCUE Toolkit: All You Need to Make Your City More Resilient}

Likewise, in order to ensure the replicability of the tools and methodologies developed within the project, RESCCUE developed the RESCCUE Toolkit (www.toolkit.resccue.eu), an interactive space where the main project results are gathered, along with the set of guidelines outlining the steps to be taken to make a city resilient.

The RESCCUE Toolkit allows the users to navigate through the different guidelines and find out all the project results, including a best practice e-book manual [36], databases, tools, methodologies and templates (Figure 11). Besides, from the RESCCUE Toolkit the user can access the RESCCUE maps on the Clarity portal and interact with them. Finally, general information on the three case studies can be found as well as extra materials, such as scientific publications, maps and deliverables of the RESCCUE project.
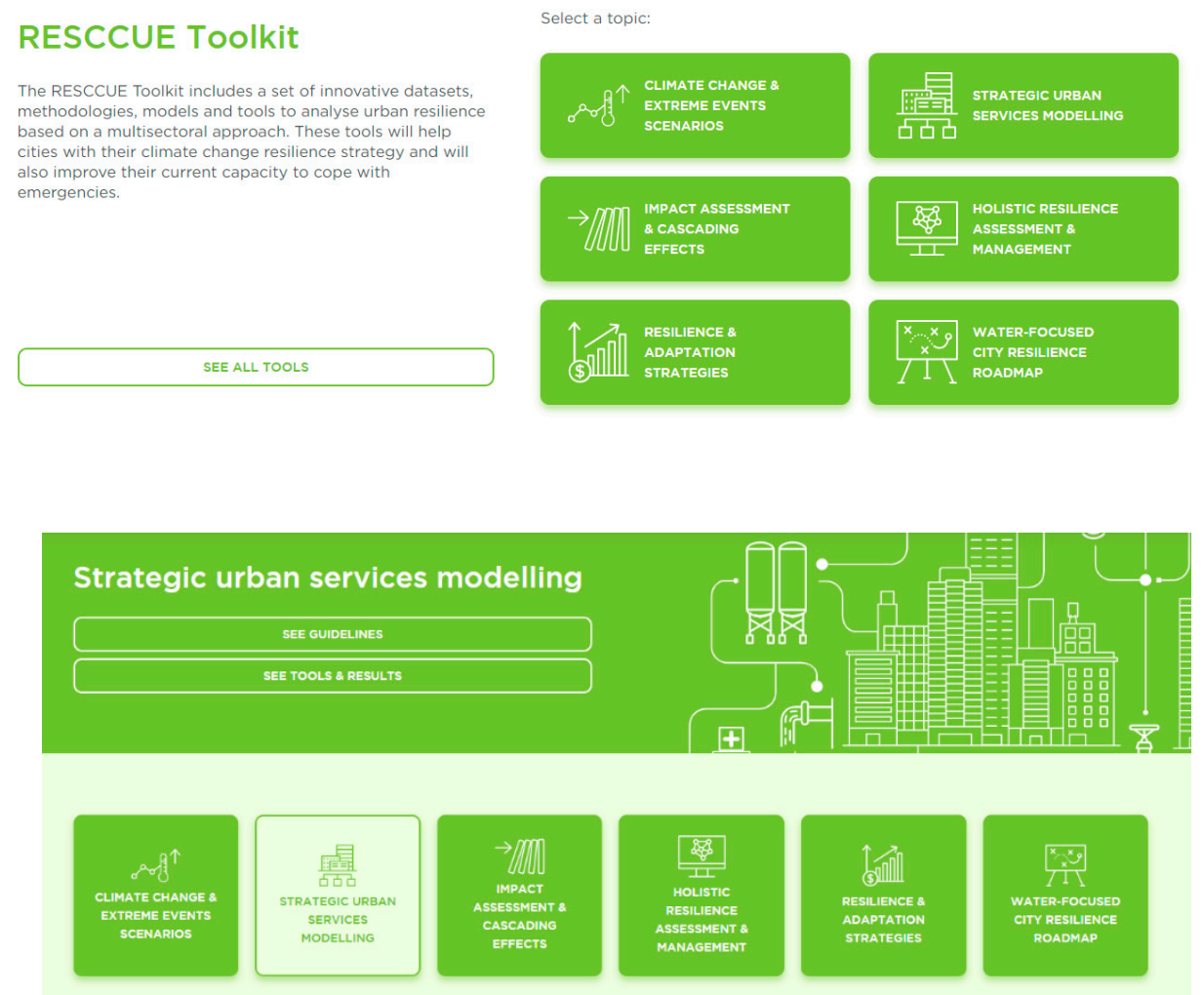

Use these guidelines to:

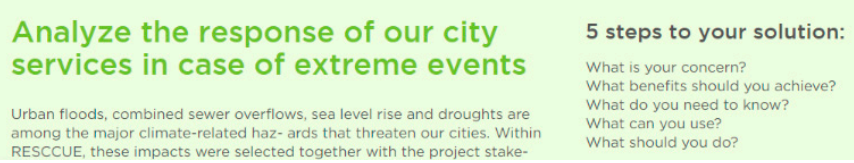

Figure 11. Screenshots of the RESCCUE Toolkit website.

This platform showcases all the tools, datasets, and methodologies developed within RESCCUE sorted by topic and by the three case studies: Barcelona, Lisbon, and Bristol. The user can select one topic - related to each WP-and see the guidelines related to it, as well as the main results and expert contact info. Besides, the user can also see the specific results for each city, including a brief description of the case study and the main tools and databases developed on it. 


\section{Conclusions}

After four and a half years of hard work and thanks to the involvement of a multidisciplinary team of experts, the RESCCUE project has produced a huge amount of results. As presented in this paper, a lot of work has been done in order to help cities increase their resilience to climate change.

RESCCUE will have a significant impact on the urban resilience sector in Europe because the methodologies and tools developed to enable city resilience assessment, planning and management, can be easily used elsewhere so other cities can replicate the RESCCUE results. Therefore, what has been presented here for Barcelona, Bristol and Lisbon, is now ready to be replicated to any other city, taking advantage of the team of experts from RESCCUE and the RESCCUE Toolkit.

As most of the world population will end up living in cities, it is critical and highly urgent to have tools available to assess, plan, and monitor urban resilience in an integral way. This urgency, justified by the already proven climate change effects, will favor the rapid deployment of RESCCUE's tools.

What RESCCUE has produced is only the beginning. The work initiated in RESCCUE will continue to move forward and cities will become more and more prepared for the coming challenges.

Author Contributions: M.V. has been the Coordinator of the RESCCUE Project, leader of WP4 and WP8. R.M. and C.P. have been the leaders of WP1. B.R. has been the leader of WP2. S.D. and B.E. have been the leaders of WP3. E.M.-G. and M.G.-H. have been the leaders of WP5. M.A.C. and R.S.B. have been the leaders of WP6. D.P. has been the leader of WP7. All authors have read and agreed to the published version of the manuscript.

Funding: This research was funded by Horizon2020 Programme, Grant Agreement No. 700174.

Acknowledgments: This paper presents some of the results achieved in the framework of the RESCCUE project (Resilience to Cope with Climate Change in Urban Areas-A multisectoral approach focusing on water) (www.resccue.eu). RESCCUE is a research project funded by the European Commission under the H2020 program, and its main goal is to provide methodologies and tools for the evaluation, planning and management of urban resilience in the context of climate change.

Conflicts of Interest: The authors declare no conflict of interest.

\section{References}

1. United Nations, Department of Economic and Social Affairs, Population Division. World Urbanization Prospects: The 2014 Revision, Highlights 2014, (ST/ESA/SER.A/352); UN: New York, NY, USA, 2014.

2. ARUP. International Development and the Rockefeller Foundation. In City Resilience and the City Resilience Framework; ARUP: London, UK, 2015.

3. Rockefeller Foundation. 100 Resilient Cities. Available online: http://www.100resilientcities.org/ (accessed on 28 June 2018).

4. Velasco, M.; Russo, B.; Martínez, M.; Malgrat, P.; Monjo, R.; Djordjevic, S.; Fontanals, I.; Vela, S.; Cardoso, M.A.; Buskute, A. Resilience to cope with climate change in Urban Areas-A multisectorial approach focusing on water-The RESCCUE Project. Water 2018, 10, 1356. [CrossRef]

5. Ribalaygua, J.; Torres, L.; Pórtoles, J.; Monjo, R.; Gaitán, E.; Pino, M.R. Description and validation of a two-step analogue/regression downscaling method. Theor. Appl. Climatol. 2013, 114, 253-269. [CrossRef]

6. Monjo, R.; Caselles, V.; Chust, G. Probabilistic correction of RCM precipitation in the Basque Country (Northern Spain). Theor. Appl. Climatol. 2014, 117, 317-329. [CrossRef]

7. Monjo, R.; Gaitán, E.; Pórtoles, J.; Ribalaygua, J.; Torres, L. Changes in extreme precipitation over Spain using statistical downscaling of CMIP5 projections. Int. J. Climatol. 2016, 36, 757-769. [CrossRef]

8. Redolat, D.; Monjo, R.; Paradinas, C.; Pórtoles, J.; Gaitán, E.; Prado-López, C.; Ribalaygua, J. Local decadal prediction according to statistical/dynamical approaches. Int. J. Climatol. 2020, 40, 5671-5687. [CrossRef]

9. Monjo, R.; Royé, D.; Martin-Vide, J. Meteorological drought lacunarity around the world and its classification. Earth Syst. Sci. Data 2020, 12, 741-752. [CrossRef]

10. Turner, B.L.; Kaspersonb, R.C.; Matsone, P.A.; McCarthy, J.; Corell, R.; Christensene, L.; Eckley, N.; Kasperson, J.X.; Luers, A.; Martello, M.L.; et al. A framework for vulnerability analysis in sustainability science. Proc. Natl. Acad. Sci. USA 2003, 100, 8074-8079. [CrossRef] 
11. Russo, B.; Velasco, M.; Monjo, R.; Martínez-Gomariz, E.; Sánchez, D.; Domínguez, J.L.; Gabàs, A.; Gonzalez, A. Evaluación de la resiliencia de los servicios urbanos frente a episodios de inundación en Barcelona. El Proyecto RESCCUE. Ing. del Agua 2020, 24, 101. [CrossRef]

12. Forero-Ortiz, E.; Martínez-Gomariz, E.; Monjo, R. Climate Change Implications for Water Availability: A Case Study of Barcelona City. Sustainability 2020, 12, 1779. [CrossRef]

13. Russo, B.; Velasco, M.; Locatelli, L.; Sunyer, D.; Yubero, D.; Monjo, R.; Martínez-Gomariz, E.; Forero-Ortiz, E.; Sánchez-Muñoz, D.; Evans, B.; et al. Assessment of urban flood resilience in Barcelona for current and future scenarios. The RESCCUE project. Sustainability 2020, 12, 5638. [CrossRef]

14. Stevens, J.; Henderson, R.; Webber, J.; Evans, B.; Chen, A.; Djordjević, S.; Sánchez-Muñoz, D.; Domínguez-García, J. Interlinking Bristol based models to build resilience to climate change. Sustainability 2020, 12, 3233. [CrossRef]

15. Almeida, M.D.; Telhado, M.J.; Morais, M.; Barreiro, J.; Lopes, R. Urban resilience to flooding: Triangulation of methods for hazard identification in urban areas. Sustainability 2020, 12, 2227. [CrossRef]

16. Martínez-Gomariz, E.; Russo, B.; Gómez, M.; Plumed, A. An approach to the modelling of stability of waste containers during urban flooding. J. Flood Risk Manag. 2019, 13, e12558. [CrossRef]

17. Sánchez-Muñoz, D.; Domínguez-García, J.L.; Martínez-Gomariz, E.; Russo, B.; Stevens, J.; Pardo, M. Electrical grid risk assessment against flooding in Barcelona and Bristol cities. Sustainability 2020, 12, 1527. [CrossRef]

18. Evans, B.; Chen, A.S.; Djordjevi, S.; Webber, J.; Gonzalez, A.; Stevens, J. Investigating the Effects of Pluvial Flooding and Climate Change on Traffic Flows in Barcelona and Bristol. Sustainability 2020, 12, 2330. [CrossRef]

19. Forero-Ortiz, E.; Martínez-Gomariz, E.; Porcuna, M.C.; Locatelli, L.; Russo, B. Flood risk assessment in an underground railway system under the impact of climate change-A case study of the Barcelona Metro. Sustainability 2020, 12, 5291. [CrossRef]

20. Guerrero-Hidalga, M.; Martínez-Gomariz, E.; Evans, B.; Webber, J.; Termes-Rifé, M.; Russo, B.; Locatelli, L. Methodology to prioritize climate adaptation measures in urban areas. Barcelona and Bristol case studies. Sustainability 2020, 12, 4807. [CrossRef]

21. Martínez-Gomariz, E.; Guerrero-Hidalga, M.; Russo, B.; Yubero, D.; Gómez, M.; Castán, S. Desarrollo y aplicación de curvas de daño y estanqueidad para la estimación del impacto económico de las inundaciones en zonas urbanas españolas. Ing. del Agua 2019, 23, 229. [CrossRef]

22. Martínez-Gomariz, E.; Forero-Ortiz, E.; Guerrero-Hidalga, M.; Castán, S.; Gómez, M. Flood Depth-Damage Curves for Spanish Urban Areas. Sustainability 2020, 12, 2666. [CrossRef]

23. Martínez-Gomariz, E.; Gómez, M.; Russo, B.; Sánchez, P.; Montes, J.A. Methodology for the damage assessment of vehicles exposed to flooding in urban areas. J. Flood Risk Manag. 2019, 12, 1-15. [CrossRef]

24. Martínez-Gomariz, E.; Gómez, M.; Russo, B. Experimental study of the stability of pedestrians exposed to urban pluvial flooding. Nat. Hazards 2016, 82, 1259-1278. [CrossRef]

25. Chen, A.S.; Hammond, M.J.; Djordjević, S.; Butler, D.; Khan, D.M.; Veerbeek, W. From hazard to impact: Flood damage assessment tools for mega cities. Nat. Hazards 2016, 82, 857-890. [CrossRef]

26. Cardoso, M.A.; Brito, R.S.; Pereira, C.; Gabàs, A.; González Gómez, A.; Goodey, P.; Lopes, R.; Martínez, M.; Russo, B.; Telhado, M.J.; et al. Resilience Action Plans of the RESCCUE Cities; D6.2 RESCCUE Project (Public); RESCCUE: Lisbon, Portugal, 2020.

27. Cardoso, M.A.; Telhado, M.J.; Almeida, M.C.; Brito, R.S.; Pereira, C.; Barreiro, J.; Morais, M. Following a step by step development of a Resilience Action Plan. Sustainability 2020, 12, 9017. [CrossRef]

28. González, A.; Gabàs, A.; Cardoso, M.A.; Brito, R.S.; Pereira, C.; Russo, B.; Martínez, M.; Velasco, M.; Domínguez, J.L.; Sánchez-Muñoz, D.; et al. Barcelona Resilience Action Plan. In Resilience Action Plans of the RESCCUE Cities; D6.2 RESCCUE Project (Public); RESCCUE: Barcelona, Spain, 2020.

29. Stevens, J.; Goodey, P.; Cardoso, M.A.; Brito, R.S.; Pereira, C.; Henderson, R.; Colclough, G.; Evans, B.; Chen, A.; Gibson, M.; et al. Bristol Resilience Action Plan. In Resilience Action Plans of the RESCCUE Cities; D6.2 RESCCUE Project (Public); RESCCUE: Bristol, UK, 2020.

30. Telhado, M.J.; Morais, M.; Cardoso, M.A.; Brito, R.S.; Pereira, C.; Lopes, R.; Barreiro, J.; Pimentel, N.; Silva, I.C.; Duarte, N.; et al. Lisbon Resilience Action Plan. In Resilience Action Plans of the RESCCUE Cities; D6.2 RESCCUE Project (Public); RESCCUE: Lisbon, Portugal, 2020. 
31. Evans, B.; Djordjevic, S.; Chen, A.S.; Gibson, M.; Almeida, M.C.; Telhado, M.; Morais, M.; Silva, I.C.; Duarte, N.; Martínez, E.; et al. Impact Assessments of Multiple Hazards in Case Study Areas; D3.4 RESCCUE Project (Confidential); RESCCUE: Bristol, UK, 2019.

32. Evans, B.; Djordjevic, S.; Chen, A.S.; Webber, J.; Russo, B.; Forero Ortiz, E.; Martinez, E.; Guerrero Hidalga, M.; Dominguez, J.L.; Almeida, M.C.; et al. Impact Assessments of Multiple Hazards in Case Study Areas (with Adaptation Strategies); D3.6 RESCCUE Project (Confidential); RESCCUE: Bristol, UK, 2020.

33. Russo, B.; Sunyer, D.; Locatelli, L.; Yubero, D.; Vela, S.; Martínez, E.; Martínez, G.; Palau, A.; Domínguez, G.; De Prada, M.; et al. Multi-Hazards Assessment Related to Water Cycle Extreme Events for Current Scenario; D2.2 RESCCUE Project (Confidential); RESCCUE: Barcelona, Spain, 2018.

34. Russo, B.; Sunyer, D.; Locatelli, L.; Martínez, E.; Almeida, M.C.; David, L.M.; Telhado, M.; Morais, M.; Duarte, N.; Lopes, R.; et al. Multi-Hazards Assessment Related to Water Cycle Extreme Events for Future Scenarios (Business As Usual); D2.3 RESCCUE Project (Confidential); RESCCUE: Barcelona, Spain, 2019.

35. Cardoso, M.A.; Brito, R.S.; Pereira, C.; Gonzalez, A.; Stevens, J.; Telhado, M.J. RAF Resilience Assessment Framework-A Tool to Support Cities' Action Planning. Sustainability 2020, 12, 2349. [CrossRef]

36. Brito, R.S.; Cardoso, M.A.; Pacheco, D.; Velasco, M.; González, A.; Evans, B.; Russo, B.; Martínez-Gomariz, E.; Stevens, J.; Guerrero-Hidalga, M.; et al. Resilient Cities Facing Climate Change; RESCCUE E-Book; RESCCUE Project Deliverable D6.3; RESCCUE: Lisbon, Portugal, 2020; p. 47. Available online: https: //toolkit.resccue.eu/wp-content/uploads/2020/10/RESCCUE-e-book_Final-version_EC_web.pdf/ (accessed on 12 November 2018).

Publisher's Note: MDPI stays neutral with regard to jurisdictional claims in published maps and institutional affiliations. 